\title{
Astrocytic IGF-IRs Induce Adenosine-Mediated Inhibitory Downregulation and Improve Sensory Discrimination
}

\author{
José Antonio Noriega-Prieto, ${ }^{1,7 *}$ Laura Eva Maglio, ${ }^{1,2 *}$ Jonathan A. Zegarra-Valdivia, ${ }^{3,4,5}$ Jaime Pignatelli, \\ Ana M. Fernandez, ${ }^{3,4}$ Laura Martinez-Rachadell, ${ }^{3,4}$ Jansen Fernandes, ${ }^{3,6}$ Ángel Núñez, ${ }^{1}$ Alfonso Araque, ${ }^{7}$ \\ Ignacio Torres-Alemán, ${ }^{3,4}$ and David Fernández de Sevilla ${ }^{1}$ \\ ${ }^{1}$ Departamento de Anatomía, Histología y Neurociencia, Facultad de Medicina, Universidad Autónoma de Madrid, 28029 Madrid, Spain, \\ ${ }^{2}$ Departamento de Ciencias Médicas Básicas (Fisiología) and Instituto de Tecnologías Biomédicas, Universidad de La Laguna, 38071 San Cristóbal \\ de La Laguna, Tenerife, Spain, ${ }^{3}$ Instituto Cajal, Consejo Superior de Investigaciones Científicas, 28002 Madrid, Spain, ${ }^{4}$ Centro de Investigación \\ Biomédica en Red sobre Enfermedades Neurodegenerativas, 28031 Madrid, Spain, ${ }^{5}$ Universidad Nacional de San Agustín de Arequipa, 04001 \\ Arequipa, Perú, ${ }^{6}$ Universidade Federal de São Paulo, São Paulo 04021-001, Brazil, and ${ }^{7}$ Department of Neuroscience, University of Minnesota, \\ Minneapolis, Minnesota 55455
}

Insulin-like growth factor-I (IGF-I) signaling plays a key role in learning and memory processes. While the effects of IGF-I on neurons have been studied extensively, the involvement of astrocytes in IGF-I signaling and the consequences on synaptic plasticity and animal behavior remain unknown. We have found that IGF-I induces long-term potentiation (LTP IGFI $)$ of the postsynaptic potentials that is caused by a long-term depression of inhibitory synaptic transmission in mice. We have demonstrated that this long-lasting decrease in the inhibitory synaptic transmission is evoked by astrocytic activation through its IGF-I receptors (IGF-IRs). We show that LTP $_{\text {IGFI }}$ not only increases the output of pyramidal neurons, but also favors the NMDAR-dependent LTP, resulting in the crucial information processing at the barrel cortex since specific deletion of IGF-IR in cortical astrocytes impairs the whisker discrimination task. Our work reveals a novel mechanism and functional consequences of IGF-I signaling on cortical inhibitory synaptic plasticity and animal behavior, revealing that astrocytes are key elements in these processes.

Key words: astrocytes; barrel cortex; IGF-I; long-term depression; long-term potentiation; sensory discrimination

Significance Statement

Insulin-like growth factor-I (IGF-I) signaling plays key regulatory roles in multiple processes of brain physiology, such as learning and memory. Yet, the underlying mechanisms remain largely undefined. Here we demonstrate that astrocytes respond to IGF-I signaling, elevating their intracellular $\mathrm{Ca}^{2+}$ and stimulating the release of ATP/adenosine, which triggers the LTD of cortical inhibitory synapses, thus regulating the behavioral task performance related to cortical sensory information processing. Therefore, the present work represents a major conceptual advance in our knowledge of the cellular basis of IGF-I signaling in brain function, by including for the first time astrocytes as key mediators of IGF-I actions on synaptic plasticity, cortical sensory information discrimination and animal behavior.

\section{Introduction}

Insulin-like growth factor-I (IGF-I) is a peptide involved in learning and memory (Ross, 2005; Aleman and Torres-Alemán, 2009). Indeed, a deficiency in circulating IGF-I results
(Nishijima et al., 2010) in an impairment of the processing speed and deficiencies in both spatial and working memories (Deijen et al., 1996; Lijffijt et al., 2003; Sytze van Dam, 2005; KoltowskaHäggström et al., 2006; Adamsky et al., 2018), whereas replacing through the National Fund for Scientific and Technological Development (FONDECYT, Perú). J.F. received a postdoctoral fellowship from Fundação de Amparo à Pesquisa do Estado de São Paulo (FAPESP; Grants \#2017) 14742-0 and \#2019/03368-5). We thank the University of Minnesota Viral Vector and Cloning Core for production of some of the viral vectors used in this study; and Dr. G. Perea and Dr. Washington Buño for helpful comments.

*J.A.N.-P. and L.E.M. contributed equally to this research.

The authors declare no competing financial interests.

Correspondence should be a addressed to David Fernández de Sevilla at david.fernandezdesevilla@uam.es.

https://doi.org/10.1523/JNEUROSCI.0005-21.2021

Copyright $\odot 2021$ the authors 
IGF-I reverses many of these cognitive deficits (Trejo et al., 2007). IGF-I regulates neuronal firing (Nuñez et al., 2003; Gazit et al., 2016) and modulates excitatory synaptic transmission in many areas of the brain (Nilsson et al., 1988; Araujo et al., 1989; Castro-Alamancos and Torres-Aleman, 1993; Seto et al., 2002; Maya-Vetencourt et al., 2012). IGF-I produces a long-lasting depression of glutamate-mediated GABA release by Purkinje cells in the cerebellum (Castro-Alamancos and Torres-Aleman, 1993) or a long-term potentiation (LTP) of GABA release in the olfactory bulb (Liu et al., 2017). However, whether IGF-I is involved in the long-lasting plasticity of inhibitory synaptic transmission in the neocortex remains unexplored.

The level of IGF-I modulates the plasticity of the somatosensory cortex in rats exposed to sensory motor restriction (Mysoet et al., 2015). The barrel cortex is the area of the somatosensory cortex involved in processing tactile information coming from the vibrissae, which is an extremely important factor in survival (Carvell and Simons, 1990). Interestingly, the uptake of IGF-I by the brain correlates with frequency-dependent changes in cerebral blood flow in the barrel cortex during whisker stimulation (Nishijima et al., 2010), indicating that IGF-I-induced plasticity at the barrel cortex is crucial in information processing in this cortical area. Moreover, somatosensory cortex astrocytes respond to sensory stimuli and regulate the sensory-evoked neuronal network (Lines et al., 2020). Indeed, astrocytes are of key importance in the induction of the long-term modulation of excitatory synaptic transmission induced by the spike timing-dependent protocol (Andrade-Talavera et al., 2016). They respond with $\mathrm{Ca}^{2+}$ elevations to neurotransmitters released by neurons and induce changes in neuronal excitability and synaptic transmission by releasing gliotransmitters (Araque et al., 2001; Nedergaard et al., 2003; Volterra and Meldolesi, 2005; Haydon and Carmignoto, 2006; Perea et al., 2009; Parpura and Zorec, 2010; Singh et al., 2014). In addition to glutamate, astrocytes also release ATP that in turn depresses excitatory synaptic transmission in the hippocampus (Serrano et al., 2006; Andersson et al., 2007; Chen et al., 2013). Moreover, in the neocortex, the exocytosis of ATP from astrocytes leads to a short-term downregulation of inhibitory synaptic currents by inhibiting postsynaptic and extrasynaptic $\mathrm{GABA}_{\mathrm{A}}$ receptors in layer II/III pyramidal neurons (Lalo et al., 2014). Further, astrocytes can release IGF-I (Chisholm and Sohrabji, 2016), and several studies have shown the presence of IGF-I and IGF-I receptors (IGF-IRs) in neurons, astrocytes, and microglia (Ocrant et al., 1988; Zhou et al., 1999; Garwood et al., 2015; Rodriguez-Perez et al., 2016). However, the effect of astrocytic IGF-IR activation on the long-term synaptic plasticity in the barrel cortex is yet to be elucidated.

Here, we have investigated whether astrocytic IGF-IR activation is participating in long-term synaptic transmission changes. We found that IGF-I induces an LTP of the postsynaptic potentials [PSPs $\left(\mathrm{LTP}_{\mathrm{IGFI}}\right)$ ] that matches a presynaptic long-term depression (LTD) of IPSCs that depend on an increase in cytosolic calcium in the astrocytes, and the activation of $\mathrm{A}_{2 \mathrm{~A}}$ adenosine receptors. This LTD is absent in mice in which the IGF-IR has been deleted specifically in astrocytes (IGF-IR ${ }^{-1-}$ mice). We

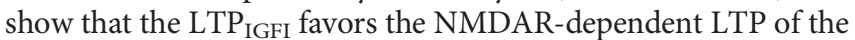
PSPs, in contrast to IGF-IR ${ }^{-1-}$ mice that show impairment in their performance of a whisker discrimination task. We show that the activation of astrocytes by IGF-I is essential for inducing Hebbian plasticity. Therefore, we present a novel mechanism of long-term synaptic depression of inhibition at the barrel cortex induced by the activation of astrocytic IGF-IRs and ATP/adenosine (ATP/Ado) release from astrocytes that have an important impact on the processing of somatosensory information occurring during the whisker discrimination task.

\section{Materials and Methods \\ Materials}

2-(2-Furanyl)-7-(2-phenylethyl)-7H-pyrazolo[4,3-e][1,2,4] triazolo [1,5-c] pyrimidin-5-amine [SCH58261 (SCH), $100 \mathrm{nM}$ ], 8-cyclopentyltheophylline (CPT; $5 \mu \mathrm{M}$ ) and BAPTA-AM (acetyloxymethyl ester; $10 \mu \mathrm{M}$ ) were purchased from Tocris Bioscience. NVP AEW541 (NVP; 400 nM) was purchased from Cayman Chemical. Recombinant human IGF-I (IGF-I; $10 \mathrm{nm)}$ was from Peprotech. BAPTA-K4 (40 mM) was from Santa Cruz Biotechnology. Fluo-4-AM $(2 \mu \mathrm{M})$ was purchased from Thermo Fisher Scientific, and the ATP Assay Kit was from Abcam. All the remaining drugs were purchased from Sigma-Aldrich (CNQX, $20 \mu \mathrm{M}$; D-AP5, $50 \mathrm{M}$ ).

\section{Key resources table}

Bacterial and virus strains. The bacterial and virus strains used were as follows: AAV8-GFAP-mCherry $\left[3.13 \times 10^{13}\right.$ genome copies $\left.(\mathrm{GC}) / \mathrm{ml}\right]$ and AAV8-GFAP-mCherry-CRE $\left(3.8 \times 10^{12} \mathrm{GC} / \mathrm{ml}\right)$ were from University of Minnesota (UMN) Viral Vector and Cloning Core; and AAV5-pZac2.1-gfaABC1D-cyto-GCAMP6f $\left(7 \times 10^{12}\right.$ viral genomes $\left./ \mathrm{ml}\right)$ were from the Penn Vector Core.

Experimental models: organisms/strains. The organisms and strains used were as follows: IGF-IR flox/flox (stock \#012251, The Jackson Laboratory); and CreERT2.GFAP (stock \#012849, The Jackson Laboratory).

\section{Ethics statement and animals}

All animal procedures were approved by the Ethical Committee of the Universidad Autónoma of Madrid, Cajal Institute, and the University of Minnesota Animal Care and Use Committee and are in accordance with Spanish Directives (R.D. 1201/2005) and European Community Directives (86/609/EEC and 2003/65/EC), and the National Institutes of Health Guidelines for the Care and Use of Laboratory Animals. Male C57BL/6J or transgenic mice were housed under a $12 \mathrm{~h}$ light/dark cycle with up to five animals per cage and were used for slice electrophysiology. Transgenic mice with a deletion of IGF-IR in astrocytes (GFAP-

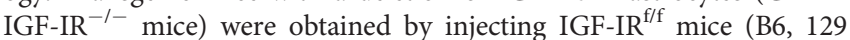
background; The Jackson Laboratory) with AAV8-GFAP-mCherry (UMN Viral Vector and Cloning Core) or AAV8-GFAP-mCherry-CRE viral vectors (UNC Vector Core). In the Behavioral studies, adult male and female control mice (C57BL/6JolaHsd; age, 6-12 months; weight, $28-35 \mathrm{~g}$ ) and transgenic mice were used. Transgenic mice with tamoxifen-regulated deletion of IGF-IR in astrocytes (IGF-IR ${ }^{-1-}$ mice) were obtained by crossing IGF-IR ${ }^{\mathrm{f} / \mathrm{f}}$ mice (B6, 129 background; IGF-IRflox/ flox mice; stock \#012251, The Jackson Laboratory) with CreERT2.GFAP mice (C57\&B/6xSJL/J mixed background; stock \#012849, The Jackson Laboratory; Ganat et al., 2006).

\section{Slice preparation}

Barrel cortex slices were prepared as described previously (Díez-García, 2017). Briefly, the mice were killed, and their brains submerged in cold $\left(4^{\circ} \mathrm{C}\right)$ cutting solution containing the following (in $\mathrm{mm}$ ): 189.0 sucrose, 10.0 glucose, $26.0 \mathrm{NaHCO}_{3}, 3.0 \mathrm{KCl}, 5.0 \mathrm{Mg}_{2} \mathrm{SO}_{4}, 0.1 \mathrm{CaCl}_{2}$, and 1.25 $\mathrm{NaH}_{2} \mathrm{PO}_{4} \cdot 2 \mathrm{H}_{2} \mathrm{O}$. Coronal slices ( $350 \mu \mathrm{m}$ thick) were cut using a vibratome (model VT $1200 \mathrm{~S}$, Leica), and incubated $\left(>1 \mathrm{~h}\right.$, at $\left.25-27^{\circ} \mathrm{C}\right)$ in artificial CSF (ACSF) containing the following (in $\mathrm{mm}$ ): $124.00 \mathrm{NaCl}, 2.69$ $\mathrm{KCl}, 1.25 \mathrm{KH}_{2} \mathrm{PO}_{4}, 2.00 \mathrm{Mg}_{2} \mathrm{SO}_{4}, 26.00 \mathrm{NaHCO}_{3}, 2.00 \mathrm{CaCl}_{2}$, and 10.00 glucose). The $\mathrm{pH}$ was stabilized at 7.3 with a $95 \% \mathrm{O}_{2}, 5 \% \mathrm{CO}_{2}$ mixture. The slices were transferred to a $2 \mathrm{ml}$ chamber fixed to an upright microscope stage (model BX51WI, Olympus) equipped with infrared differential interference contrast (DIC) video microscopy and superfused at room temperature with $95 \% \mathrm{O}_{2}, 5 \% \mathrm{CO}_{2}$-bubbled ACSF ( $2 \mathrm{ml} / \mathrm{min}$ ).

Electrophysiological recordings in slices

Patch-clamp recordings from layer II/III pyramidal neurons of the barrel cortex were performed in whole-cell voltage-clamp and current-clamp configurations, as described previously (Díez-García, 2017). Briefly, patch pipettes (4-8 $\mathrm{M} \Omega$ ) were filled with an internal solution that 
contained the following (in mM): $135 \mathrm{KMeSO}_{4}, 10 \mathrm{KCl}, 10 \mathrm{HEPES}-\mathrm{K}, 5$ $\mathrm{NaCl}, 2.5 \mathrm{ATP}-\mathrm{Mg}^{+2}$, and $0.3 \mathrm{GTP}-\mathrm{Na}^{+}, \mathrm{pH}$ 7.3. In some experiments, the following BAPTA-based intracellular solution was used (in $\mathrm{mM}$ ): 40 BAPTA-K ${ }_{4}, 2$ ATP-Na ${ }^{2+}, 10$ mm HEPES, $1 \mathrm{MgCl}_{2}$, and $8 \mathrm{NaCl}$, pH 7.3. The holding potential was adjusted in a range from -70 to $-80 \mathrm{mV}$, and series resistance was compensated to $\sim 80 \%$. Layer II/III pyramidal neurons located over the barrels (layer IV) were accepted only when the seal resistance was $>1 \mathrm{G} \Omega$ and the series resistance (10-20 M $\Omega$ ) did not change ( $>20 \%$ ) during the experiment. IPSCs were isolated in the presence of AMPAR and NMDAR antagonists $(20 \mu \mathrm{M} C N Q X$ and $50 \mu \mathrm{M} \mathrm{D}-$ AP5, respectively). IPSCs were evoked with a bipolar stimulation electrode pulled from a theta borosilicate glass capillary (tip diameter, 5-8 $\mu \mathrm{m}$ ), filled with ACSF, and connected to a stimulator (model S88, Grass) and a stimulus isolation unit (Quincy Digital) through chloride-silver electrodes. The stimulating electrodes were placed at layer IV of the barrel cortex near the tip $(\sim 100-150 \mu \mathrm{m})$ of the recording pipette. Paired pulses (duration, $200 \mu \mathrm{s}$; interval, $50 \mathrm{~ms}$ ) were continuously delivered at $0.33 \mathrm{~Hz}$. After recording $5 \mathrm{~min}$ of stable baseline of the IPSCs, IGF-I was added to the bath for $35 \mathrm{~min}$. To check for the induction of long-lasting synaptic plasticity, the IGF-I was washed for at least $10 \mathrm{~min}$ and the amplitude of the IPSCs after IGF-I washout was continuously checked. The presynaptic or postsynaptic origin of the observed regulation of synaptic currents was tested by estimating changes in the paired-pulse ratio (PPR) of the IPSCs (Creager et al., 1980; Clark et al., 1994; Kuhnt and Voronin, 1994). To estimate the modification of the synaptic current variance, we calculated the noise-free coefficient of variation of the synaptic responses before (control conditions) and during IGF-I (Maglio et al., 2018).

\section{Electrophysiological recording in vivo}

We studied 3-month-old male C57BL6/J mice weighing 25-30 g. Mice were group housed in clear plastic cages under a $12 \mathrm{~h}$ light/dark cycle and given ad libitum access to food and water. Surgery and recording were performed as previously described (Díez-García, 2017). Briefly, the mice were placed in a stereotaxic device under urethane $(1.4 \mathrm{~g} / \mathrm{kg})$ in which surgical procedures and recordings were made. Local field potentials (LFPs) were obtained through tungsten microelectrodes (0.5-1 $\mathrm{M} \Omega$ ) located into the cortex. Signals were filtered $(0.3-300 \mathrm{~Hz}$ for electrocorticogram) and amplified via a preamplifier (model AC P15, Grass). After a stable baseline recording, IGF-I or saline (six applications of $84 \mathrm{nl}$, one every $5 \mathrm{~min}$, at a speed of $84 \mathrm{nl} / \mathrm{min}$ ) was administered intracranially with a syringe (Gas Tight, Hamilton) coupled to a pump controller (Microinjection Syringe Pump Controller, WPI) stereostaxically placed at layer II/III of the barrel cortex.

\section{Stereotaxic surgery and virus delivery}

Mice between 8 and 10 weeks of age were anesthetized with a ketamine $(100 \mathrm{mg} / \mathrm{kg}) / x y l a z i n e(10 \mathrm{mg} / \mathrm{kg}) \mathrm{mix}$. To selectively delete the IGF-IRs in cortical astrocytes, IGF-IR ${ }^{\mathrm{f} / \mathrm{f}}$ mice were injected in the barrel cortex with $500 \mathrm{nl}$ of the viral vector AAV8-GFAP-mCherry-CRE (or AAV8GFAP-mCherry as a control). To monitor the astrocyte calcium levels, the mice were injected with $500 \mathrm{nl}$ of AAV5-pZac2.1-gfaABC1D-cytoGCAMP6f (Penn Vector Core). Injections were made at layer II/III of barrel cortex with a Hamilton syringe attached to a 29 gauge needle at a rate of $0.1 \mu \mathrm{l} / \mathrm{min}$. The coordinates used to reach the area were as follows: anteroposterior, $-1.0 \mathrm{~mm}$; mediolateral, $\pm 3.50 \mathrm{~mm}$; dorsoventral, $-0.15 \mathrm{~mm}$. Three weeks after the injection, successful delivery was confirmed by the location of the virus based on mCherry expression. Immunohistochemistry analysis confirmed the selective expression of the virus in cortical astrocytes.

\section{$\mathrm{Ca}^{2+}$ imaging}

In GFAP-IGF-IR ${ }^{-1-}$ mice and their controls, $\mathrm{Ca}^{2+}$ levels in the astrocyte soma and processes were obtained by two-photon microscopy (model DM6000 CFS upright multiphoton microscope with TCS SP5 MP laser, Leica) using the GCaMP6f viral vector targeted at astrocytes. In some experiments, the somatic $\mathrm{Ca}^{2+}$ levels were obtained using epifluorescence microscopy and the $\mathrm{Ca}^{2+}$ indicator Fluor-4-AM (5 $\mu \mathrm{M}$ in $0.01 \%$ pluronic, incubated for $30-45 \mathrm{~min}$ at room temperature). Loaded cells were illuminated every $100 \mathrm{~ms}$ at $490 \mathrm{~nm}$ with a monochromator (Polychrome IV, T.I.L.L. Photonics), and successive images were obtained at $1 \mathrm{~Hz}$ with a cooled monochrome CCD camera (Hamamatsu) attached to the Olympus microscope equipped with a filter cube (Chroma Technology). The camera control and synchronization for the epifluorescence were made by ImagingWorkbench software (INDEC BioSystems) and for two-photon imaging by LAS software (Leica).

\section{Astrocyte cultures and ATP release}

Pure astroglial cultures were prepared as described previously (Fernandez et al., 2007). Postnatal brains [postnatal day 0 (P0) to P2] from C57BL/6J [wild type (WT)] and constitutively GFAP IGF-IR ${ }^{-/-}$ mice (Hernandez-Garzón et al., 2016) were removed and immersed in ice-cold Earle's balanced salt solution (Thermo Fisher Scientific). The cortices were dissected and mechanically dissociated. The resulting cell suspension was centrifuged and plated in DMEM/F-12 (Thermo Fisher Scientific) with $10 \%$ fetal bovine serum (FBS; Thermo Fisher Scientific) and a $100 \mathrm{mg} / \mathrm{ml}$ antibiotic-antimycotic solution (Sigma-Aldrich). Cell cultures were maintained in an incubator at $37^{\circ} \mathrm{C}$ and $95 \%$ humidity with $5 \% \mathrm{CO}_{2}$. Pure astrocyte monolayer cultures were replated at $2.5 \times 10^{5}$ cells/well in DMEM/F-12 with $10 \%$ FBS medium. After $2 \mathrm{~d}$, the medium was replaced by DMEM/F-12 for $3 \mathrm{~h}$ followed by a $1 \mathrm{~h}$ treatment with $10 \mathrm{~nm}$ IGF-I (PreproTech) or a $1 \mathrm{~h}$ treatment with the following inhibitors: $400 \mathrm{~nm}$ NVP-AEW541 (IGF-I receptor antagonist, Cayman Chemical), $10 \mu \mathrm{M}$ BAPTA-AM (intercellular $\mathrm{Ca}^{2+}$ chelator, Sigma-Aldrich), followed by a $1 \mathrm{~h}$ stimulation with $10 \mathrm{~nm} \mathrm{IGF-I.}$

The amount of ATP released into the medium was measured using an ATP Assay Kit (fluorometric; catalog \#ab83355, Abcam) according to the manufacturer instructions. First, the cells were washed with cold PBS and resuspended in $100 \mu \mathrm{l}$ of ATP assay buffer. Then the cells were quickly homogenized by pipetting up and down and centrifuged for $2 \mathrm{~min}$ at $4^{\circ} \mathrm{C}(18,000 \times \mathrm{g})$ to remove any insoluble material. The supernatant was collected and transferred to a clean tube and kept on ice. An ATP assay buffer $(400 \mu \mathrm{l})$ and $100 \mu \mathrm{l}$ of ice-cold $4 \mathrm{~m}$ perchloric acid were added to the homogenate to deproteinate the samples. The homogenates were briefly vortexed and incubated on ice for $5 \mathrm{~min}$, centrifuged at $18,000 \times g$ for $2 \mathrm{~min}$ at $4^{\circ} \mathrm{C}$, and the supernatant was transferred to a fresh tube. The supernatant volume was measured, and an equal volume of ice-cold $2 \mathrm{M} \mathrm{KOH}$ was added. Finally, the homogenate was centrifuged at $18,000 \times g$ for $15 \mathrm{~min}$ at $4^{\circ} \mathrm{C}$, and the supernatant collected. ATP reaction mix $(50 \mu \mathrm{l})$ and $50 \mu \mathrm{l}$ of sample were added to each well and incubated at $24^{\circ} \mathrm{C}$ for $30 \mathrm{~min}$, protected from light. The samples were measured on a FLUOstar microplate reader (BMG LabTech) at 535/ $587 \mathrm{~nm}$. Each sample was run in duplicate. The concentrations of ATP released from the astrocyte primary cultures were obtained from standard curves and normalized to the total amount of protein.

\section{Behavioral experiments}

Adult male and female control (C57BL/6JolaHsd; age, 6-12 months; weight, 28-35 g), and transgenic mice with tamoxifen-regulated deletion of IGF-IR in astrocytes (IGF-IR ${ }^{-1-}$ mice; see above) were used. The IGF-IR activity was knocked down after the administration of tamoxifen, as described previously (Hirrlinger et al., 2006). Tamoxifen was injected for 5 consecutive days intraperitoneally ( $75 \mathrm{mg} / \mathrm{kg}$; Sigma-Aldrich) from the age of 1 month, and the mice were used at 2-7 months of age. The controls used were their siblings that had been treated only with the vehicle for tamoxifen injections (corn oil). Using the tdTomato/eGFP reporter mouse to detect Cre-mediated deletion in response to tamoxifen administration in CreERT2.GFAP mice, we previously documented that it was restricted to the astrocytes (García-Cáceres et al., 2016). Multiplex PCR for mouse genotyping included a common forward primer (P3: 5'-CTG TTT ACC ATG GCT GAG ATC TC - 3'), and two reverse primers specific for the wild-type (P4: 5'-CCA AGG ATA TAA CAG ACA CCA TT - 3') and mutant (P2: 5'-CGC CTC CCC TAC CCG GTA GAA TTC-3') alleles. The GFAP-T-IGF-IR mice showed lower levels of IGF-IR in their brains after tamoxifen injection. The mice were housed in standard cages $\left(48 \times 26 \mathrm{~cm}^{2}\right)$ with four to five animals per cage, kept in a room with controlled temperature $\left(22^{\circ} \mathrm{C}\right)$ under a $12 \mathrm{~h}$ 
light/dark cycle, and fed with a pellet rodent diet and water available ad libitum. All experimental protocols were performed during the light cycle between 14 and 18 p.m. The animal procedures followed European guidelines (2010/63/EU) and were approved by the local Bioethics Committee (Madrid Government).

$q P C R$. Total RNA isolation from their brain tissue was conducted with TRIzol. One milligram of RNA was reverse transcribed using a high-capacity cDNA reverse transcription kit (Thermo Fisher Scientific) according to the manufacturer instructions. cDNA (62.5 ng) was amplified using TaqMan probes for mouse IGF-IR, and rRNA $18 \mathrm{~S}$ as the endogenous control (Thermo Fisher Scientific). Each sample was run in triplicate in $20 \mu \mathrm{l}$ of reaction volume using a TaqMan Universal PCR Master Mix according to the manufacturer instructions (Thermo Fisher Scientific). All the reactions were performed in a 7500 Real Time PCR System (Thermo Fisher Scientific). Quantitative real-time PCR analysis was conducted as described previously (Pfaffl, 2001). The results were expressed as relative expression ratios on the basis of group means for target transcripts versus the reference $18 \mathrm{~S}$ transcript.

For the behavioral tests, both sexes were used and balanced between experimental groups. Since the wild-type mice and their control littermates performed similarly in the tests, they were pooled and presented as a single control group. We performed the following three behavioral tests.

Gap-crossing test. To assess sensory perception through the whiskers, we used the gap-crossing test, which consists of a series of trials in which the mouse has to cross a gap with increasing distances (Hutson and Masterton, 1986; Barnéoud et al., 1991). Each mouse was placed in the center of an elevated platform $(5 \mathrm{~cm}$ wide, $9 \mathrm{~cm}$ long) connected to a safe black cylindrical tube (diameter, 8 $\mathrm{cm}$; length, $9 \mathrm{~cm}$ ). The gap distance between the platform and the cylindrical tube ranged from 0 to $8 \mathrm{~cm}$ in $1 \mathrm{~cm}$ increments. The test was performed under infrared lighting, the trials were recorded with a video camera, and the maximum distance crossed by each animal was measured.

Y-maze spontaneous alternation test. Working memory was assessed by recording spontaneous activity while exploring a Y-maze (Sarter et al., 1988). The maze was made of black-painted wood, and each arm was $25 \mathrm{~cm}$ long, $14 \mathrm{~cm}$ high, $5 \mathrm{~cm}$ wide, and positioned at equal angles. The trials lasted $8 \mathrm{~min}$ each. After each trial, the maze was cleaned with $70 \%$ ethanol to remove any olfactory cues. An off-line analysis of the videos was carried out to obtain the sequence of entries during the test. Alternate behavior was calculated as the percentage of real alternations (number of triplets with nonrepeated entries) versus total alternation opportunities (total number of triplets).

Whisker discrimination test. To assess the ability of the mice to discriminate different textures with their whiskers, we adapted the two-trial Y-maze test described in previous work (Dellu et al., 2000; Hausrat et al., 2015). The apparatus was constructed of black-painted wood with three arms, each $25 \mathrm{~cm}$ long, $5 \mathrm{~cm}$ wide, and $14 \mathrm{~cm}$ high. The walls of the maze arms were covered with two different grades of black sandpaper. While two arms (familiar) were covered with a 500 grit sandpaper, the third (novel) was covered with 220 grit sandpaper. Because the three arms of the maze were identical, and there are no extramaze cues, the discrimination of novelty versus familiarity relies only on the different textures that the mouse can perceive with its whiskers. The experiments were conducted in a room with dim illumination (6 lux). During the acquisition phase, the mice were placed at the end of one of the familiar arms (in a random order) and were allowed to explore both familiar arms (500 grit sandpaper) for $5 \mathrm{~min}$ while the third arm (novel; 220 grit sandpaper) was closed with a guillotine door. At the end of the first trial, the mice were returned to their home cage for $5 \mathrm{~min}$. In the retrieval phase, the mice were again placed at the end of the same arm where they started the acquisition phase and were allowed to freely explore all three arms for $5 \mathrm{~min}$. To remove any possible olfactory cues, the maze was cleaned with $70 \%$ ethanol between the trials. The time spent in each of the arms was recorded using a video camera, and the discrimination index [novel arm/(novel + familiar arms)] $\times 100$ calculated.

\section{Data analysis}

Electrophysiological data analysis was conducted in Clampfit 10 (Axon Instrument), and ImageJ (NIH) was used for the calcium imaging. The graphs were drawn in SigmaPlot 11 (Systat Software). The fluorescence values are given as $\Delta F / F_{0}\left(\Delta F / F_{0}=100 \times\left(F-F_{0}\right) / F_{0}\right)$, where $F_{0}$ is the prestimulus fluorescence level when cells were at rest, and $F$ is the fluorescence at different times during activity. Data normality was tested using a Kolmogorov-Smirnov test. We used the Student's two-tailed $t$ tests for unpaired or paired data as required in the electrophysiology experiments. Data are presented as the mean \pm SEM. The thresholds for statistical significance were ${ }^{*} p<0.05,{ }^{* *} p<0.01$, and ${ }^{* * *} p<0.001$ for the Student's test. Statistical analysis was performed using GraphPad Prism 5.0. To compare differences between two groups and compare multiple variables, two-way ANOVA, one-way ANOVA (parametric test) or Kruskal -Wallis tests (nonparametric test) are used, followed by Holm-Sidak and Dunn tests (for parametric and nonparametric test, respectively) or Bonferroni post hoc test to compare replicate means. Statistical differences were considered at $p<0.05$. The results are presented as the mean \pm SEM of five independent experiments $(\# p<0.05$, $\# \# p<0.01$, \#\#\#p<0.001).

\section{Results}

\section{IGF-I induces LTP of PSPs (LTP IGFI $\left._{\text {I }}\right)$ at layer II/III pyramidal neurons}

The experience-dependent plasticity of barrel cortex layer IV neurons is largest when the experience is manipulated early (before P7), but the plasticity of layer II/III responses persists beyond the first week of life (Fox, 1992). During the second postnatal week, the layer IV map serves as a template for the growth and Hebbian refinement of the cortical circuitry underlying the layer II/III map, and layer IV to layer II/III feedforward excitatory projections are confined almost exclusively to one barrel column (Lübke et al., 2000). Therefore, we investigated whether IGF-I modulates the efficacy of these synapses. We recorded the PSPs at layer II/III pyramidal neurons evoked by the stimulation of layer IV (Fig. 1A). After recording $5 \mathrm{~min}$ of stable baseline of the IPSCs, IGF-I was added to the bath for $35 \mathrm{~min}$ in an attempt to mimic the long-lasting increase in serum IGF-I observed after a long-term resistance exercise (Tsai et al., 2015) and the associated increase in the IGF-I levels in the brain (Carro et al., 2000). After $5 \mathrm{~min}$ of stable recording, $10 \mathrm{~nm}$ IGF-I was applied for $35 \mathrm{~min}$. The addition of IGF-I increased the number of synaptic stimuli that evoked action potentials (APs; from $6.5 \pm 2.1$ basal to $32.6 \pm 4.5$ after $15 \mathrm{~min}$ of IGF-I application; Fig. $1 B$, $\# \# \#=0.0004)$. In addition, it also induced a potentiation of the PSPs that remained for $30 \mathrm{~min}$ after the IGF-I washout (percentage of peak amplitude: from $100.70 \pm 1.58 \%$ basal to $146.80 \pm$ $9.06 \%$ at $60 \mathrm{~min}$ after IGF-I application; Fig. $1 B,{ }^{* *} p=0.0014$ ). These IGF-I-induced effects were prevented by bath perfusion of the IGF-IR-selective inhibitor NVP-AEW 541 [number of Aps: from $6.4 \pm 0.5$ basal to $12.4 \pm 2.1$ at $15 \mathrm{~min}$ after IGF-I application $(p=0.101)$; percentage of peak amplitude: from $97.00 \pm 1.87 \%$ basal to $103.60 \pm 12.27 \%$ at $60 \mathrm{~min}$ after IGF-I application (Fig. $1 B, p=0.6472$ )], indicating that they were mediated by IGF-IR activation. Therefore, activation of IGF-IR induces an LTP of the PSPs (termed LTP $_{\text {IGFI }}$ ).

To test whether the LTP can be also induced in vivo, we recorded the extracellular LFPs at layer II/III of the barrel cortex evoked by low-frequency deflections delivered at the principal whisker (Fig. 1C). Following $15 \mathrm{~min}$ of control whisker-evoked LFP recording, IGF-I was applied in six IGF-I applications, one injection of $84 \mathrm{nl}$ IGF-I $(0.076 \mathrm{mg} / \mathrm{ml})$ every $5 \mathrm{~min}$ via a Hamilton syringe placed close to the recording electrode (see Materials and Methods). IGF-I application induced a long- 
lasting enhancement of the LFP (percentage of LFP area: from $99.45 \pm 1.80 \%$ basal to $177.60 \pm 21.00 \%$ at $80 \mathrm{~min}$ after IGF-I application; Fig. $\left.1 D,{ }^{* *} p=0.0002\right)$. This enhancement in the synaptic efficacy was absent in the controls using a saline injection (percentage of LFP area: from $99.94 \pm 0.33 \%$ basal to $90.98 \pm 10.74 \%$ at $80 \mathrm{~min}$ after IGF-I application; Fig. $1 D, p$ $=0.4317)$. Therefore, these results suggest that IGF-I induces the LTP of the synaptic potentials at layer II/III pyramidal neurons both ex vivo and in vivo.

\section{Activation of IGF-IR in astrocytes induces presynaptic LTD of IPSCs (LTD IGFI $_{\text {IG }}$}

The increase in the efficacy of the synaptic potentials could be because of the modulation of the inhibitory and/or excitatory synaptic transmission. To elucidate this issue, we first investigated whether IGF-I reduces the efficacy of inhibitory synaptic transmission. IPSCs were isolated in the presence of the glutamate receptor antagonists $20 \mu \mathrm{M}$ CNQX and $50 \mu \mathrm{M}$ AP5. After $5 \mathrm{~min}$ of IPSC recording, IGF-I was bath applied for $35 \mathrm{~min}$ and then washed out. The IGF-I induced an LTD of the IPSC peak amplitude (termed LTD $_{\text {IGFI }}$ ) that persisted after IGF-I washout (percentage of peak amplitude: from $100.60 \pm 1.42 \%$ basal to $60.73 \pm 5.08 \%$ at $60 \mathrm{~min}$ after IGF-I application; Fig. $2 A, B,{ }^{* *} p=$ $0.0002)$. The IGF-I-induced effects were prevented by NVP-AEW 541 (percentage of peak amplitude: from $98.72 \pm 0.50 \%$ basal to $96.15 \pm 3.59 \%$ at $60 \mathrm{~min}$ after IGF-I application; Fig. $2 A, p=0.9881$ ), indicating that they were mediated by IGF-IR activation. Because postsynaptic calcium increases are known to be required for the induction of long-term synaptic plasticity (Zucker, 1999), we then tested whether LTD IGFI induction required cytosolic calcium elevation in the recorded neuron. Therefore, we included the $\mathrm{Ca}^{2+}$ chelator BAPTA $(40 \mathrm{~mm})$ in the patch pipette to prevent neuronal calcium elevations. However, a similar LTD IGFI was induced in both the control and the neuron BAPTA-loaded conditions [percentage of peak amplitude: from $100.08 \pm 0.60 \%$ basal to $68.67 \pm 6.76 \%$ at $60 \mathrm{~min}$ after IGF-I application; Fig. $2 C$, BAPTAn (BAPTA in the postsynaptic neuron), $\left.{ }^{* *} p=0.0066\right]$. To test the possibility of a presynaptic origin for the effect of IGF-I, we recorded the IPSCs evoked by paired-pulse stimulation (50 ms delay) and analyzed changes in PPRs. The PPRs were increased during LTD $_{\text {IGFI }}$ recorded both in the control condition and during the BAPTA loading in neurons [percentage of PPR: from $100.00 \pm 3.23 \%$ basal to $120.37 \pm 5.33 \%\left({ }^{* *} p=0.0002\right)$ in control; and from $100.00 \pm 3.40 \%$ basal to $114.34 \pm 4.59 \%$ at $60 \mathrm{~min}$ after IGF-I application $\left({ }^{* *} p=0.0015\right)$, in postsynaptic BAPTA condition; Fig. $2 D$, control and BAPTAn], indicating the presynaptic origin of the $\mathrm{LTD}_{\mathrm{IGFI}}$. This increase in the PPR was prevented by NVP (percentage of PPR: from $100.00 \pm 3.23 \%$ basal to and in the slices.
B
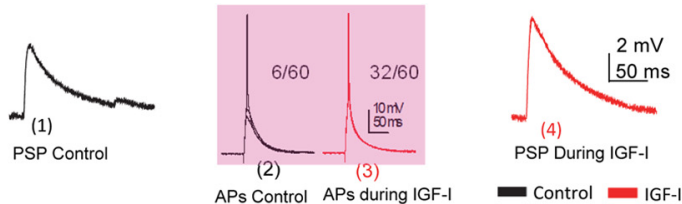

PSP During IGF-I
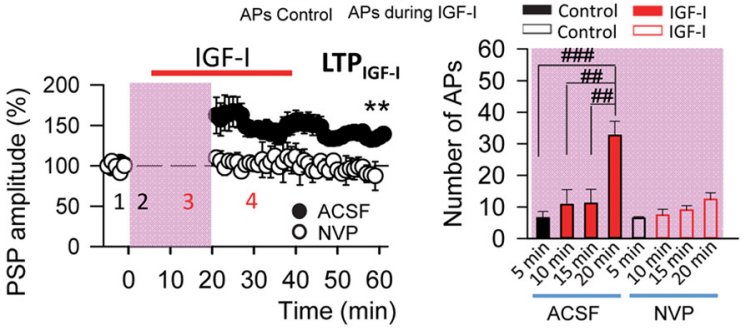

D

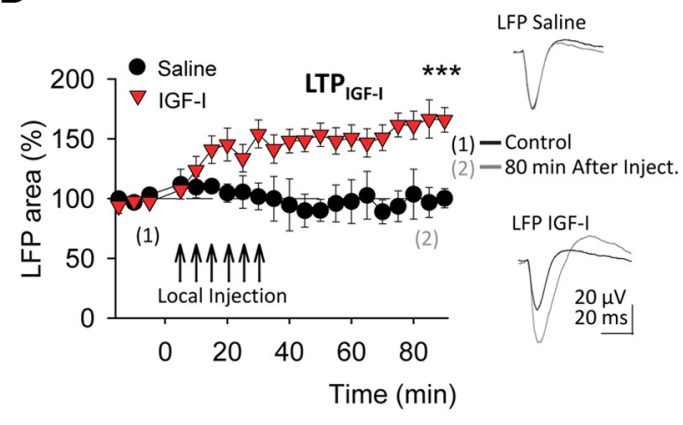

Figure 1. IGF-I induces LTP of the PSPS at layer II/III pyramidal neuron of barrel cortex. $A$, DIC image showing the record(Stim.) electrodes in a slice. Scale bar, $100 \mu \mathrm{m}$. B, Top, Representatives PSPs in control [black, [empty circles; $n=5$ cells/2 animals; NVP vs NVP+IGF-I, ns (nonsignificant)]. Two-tailed Student's paired $t$ test. Right,

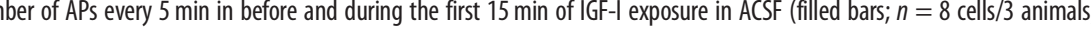
animals; NVP vs NVP+IGF-I, ns; $\left.F_{(3,16)}=2687\right)$ One-way ANOVA.C Top, Time course scheme showing the local injections cording electrode and Hamilton syringe location, and air puff stimulation. $\boldsymbol{D}$, Left, Time course of LFP recorded in mice saline, ns) two-tailed Student's paired t test. Right, Representative superimposed LFPs recorded in the control [black, $(1)]$

$99.95 \pm 14.00 \%$ at 60 min after IGF-I application; $p=0.9636$; Fig. $2 D, N V P)$. Together, these data suggest that IGF-I induces a presynaptic LTD of IPSCs, which do not require cytosolic calcium elevations in the recorded postsynaptic neuron.

Astrocytes are emerging as important cells involved in the regulation of synaptic transmission and plasticity (Araque et al., 2014) that are able to regulate inhibitory synaptic transmission in the hippocampus (Kang et al., 1998). Therefore, we investigated whether LTD $_{\text {IGFI }}$ requires cytosolic calcium elevations in astrocytes. The application of IGF-I induced an increase in the frequency of astrocyte calcium elevations (from $0.71 \pm 0.09$ basal to $1.35 \pm 0.12$ after IGF-I application; Fig. $3 A$, control, ${ }^{\star *} p=$ 0.0023 ) that was absent under NVP (from $0.98 \pm 0.10$ basal to $1.00 \pm 0.05$ after IGF-I application; $p=0.8909$; Fig. $3 A, \mathrm{NVP}$ ). We then tested whether the IGFI-induced enhancement of the astrocyte calcium signal contributed to the $\mathrm{LTD}_{\mathrm{IGFI}}$. We prevented the $\mathrm{Ca}^{2+}$ signal selectively in astrocytes by recording a cortical astrocyte with a patch pipette containing $40 \mathrm{~mm}$ BAPTA. Since cortical astrocytes are gap junction connected, injecting BAPTA into a single astrocyte can diffuse through a large 
A

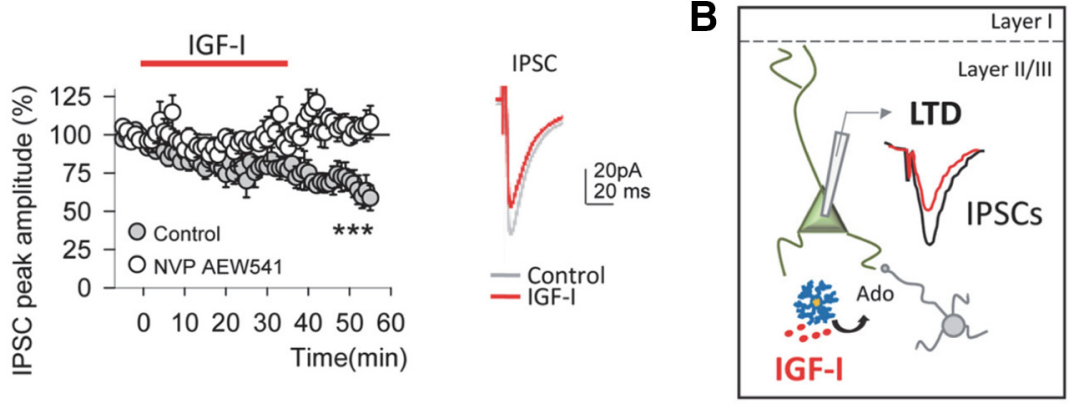

C

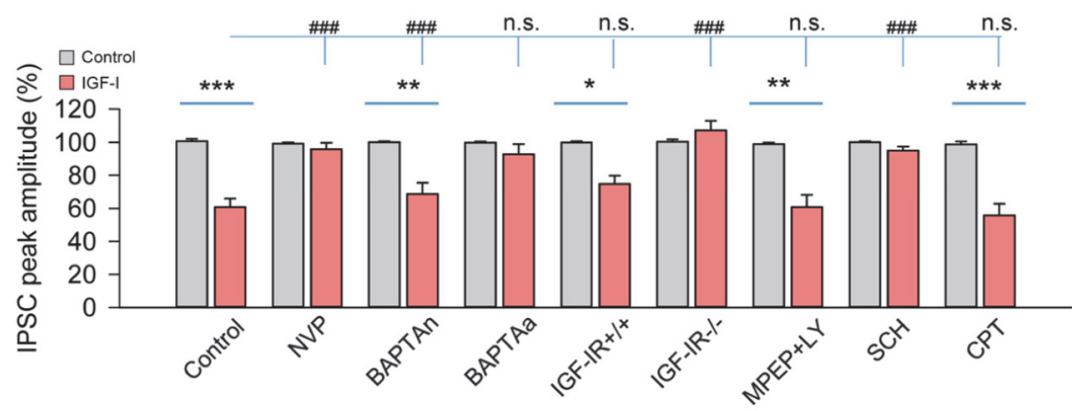

D

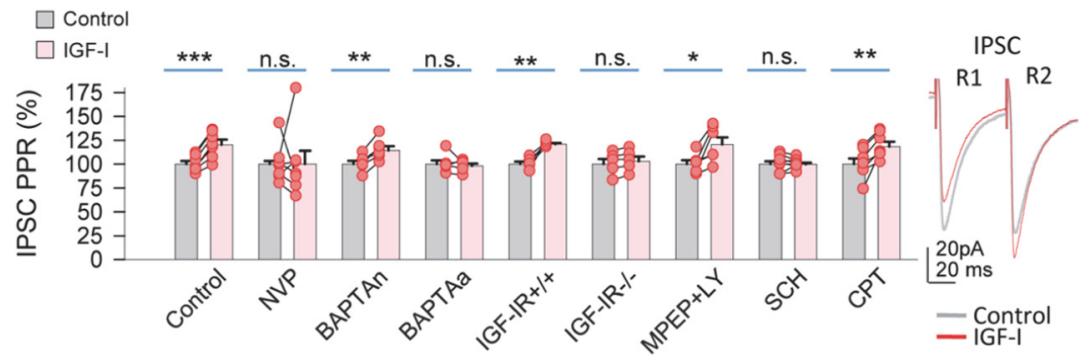

Figure 2. Astrocytic IGF-IR activation induces adenosine-mediated LTD of the IPSCS. $\boldsymbol{A}$, Time course of the IPSC peak amplitude before, during, and after washing out of IGF-I in ASCF (control, empty circles; $n=7$ cells/4 animals; control vs IGF-I, ${ }^{* *} p<0.001$ ), and in the presence of NVP-AEW 541 [gray circles; $n=7$ cells/3 animals; NVP vs NVP+IGF-I, ns (nonsignificant), two-tailed Student's paired $t$ test]. Right, Representative IPSCs in control (gray) and after $20 \mathrm{~min}$ of IGF-I washout (red). $\boldsymbol{B}$, Cartoon showing that the LTD of the IPSCs induced by IGF-I in layer II/III pyramidal neurons (green cell) depends on the IGF-IR activation on astrocytes (orange cell with blue processes) and the adenosine receptor-mediated reduction of GABA release form the GABAergic interneurons (gray cell). C, Effect of IGF-I on the IPSC peak amplitude (red bar), as a percentage of the control (gray bar), in different experimental conditions, as follows: ACSF, NVP, BAPTAn $(n=6$ cells $/ 3$ animals; control vs IGF-I, ${ }^{* *} p<0.01$ ), BAPTA loaded astrocyte (BAPTAa; $n=6$ cells $/ 3$ animals; control vs IGF-I, ${ }^{* *} p<0.01$ ), ACSF in the IGF-IR ${ }^{-I-}$ mice $\left(n=5\right.$ cells/2 animals; control vs IGF-I, ns) and its littermates (IGF-IR ${ }^{+/+} ; n=5$ cells $/ 2$ animals; control vs IGF-I, $\left.{ }^{*} p<0.05\right)$, MPEP + LY 367385 ( $n=6$ cells $/ 3$ animals; MPEP + LY vs MPEP + LY + IGF-I, $\left.{ }^{* *} p<0.01\right), S C H$ ( $n=8$ cells $/ 4$ animals; SCH vs SCH+IGF-I, ns), and CPT ( $n=7$ cells/2 animals; CPT vs CPT +IGF-I, ${ }^{* *} p<0.001$, two-tailed Student's paired $t$ test). Note that the LTD of the IPSCS by IGF-I is prevented when IGF-IRs are absent on astrocytes or when they are filled with BAPTA, and when adenosine $A_{2}$ receptors or IGF-I receptors are blocked by CPT and NVP, respectively. $\boldsymbol{D}$, Left, Effect of IGF-I on the IPSC PPR (red bar), as a percentage of the control (gray bar), in the same different experimental conditions of $\boldsymbol{C}$. Right, Representative IPSCs evoked by paired pulses recorded before (gray trace, control) and during IGF-I (red trace, IGF-I). Note that IGF-I increases the PPR (R2/R1) because it reduces the first IPSC (R1) more than the second IPSC (R2). ${ }^{\# \#} p<0.001$.

extension of the gap junction-coupled astrocytic network (Navarrete and Araque, 2010). However, BAPTA loading the astrocytic network, IGF-I failed to modulate the IPSCs [percentage of peak amplitude: from $99.79 \pm 0.62 \%$ basal to $92.75 \pm$ $6.20 \%$ at $60 \mathrm{~min}$ after IGF-I application; $p=0.3222$; Fig. $2 C$, BAPTAa (BAPTA loaded astrocyte)] or the PPR (percentage of PPR: from $100.00 \pm 3.86 \%$ basal to $98.01 \pm 2.48 \%$ at $60 \mathrm{~min}$ after IGF-I application; $p=0.5896$; Fig. $2 D$, BAPTAa). Therefore, these data suggest that cytosolic $\mathrm{Ca}^{2+}$ increases in the astrocytes, not in the postsynaptic neurons, are essential for the induction of LTD IGFI.

Although LTD IGFI requires astrocyte calcium elevations, astrocyte stimulation by IGF-I could occur directly either through the activation of astrocytic receptors, or indirectly through the activation of neuronal receptors that trigger an indirect signaling pathway. To discriminate between these two possibilities, we deleted IGF-IR specifically in astrocytes using a combined viral and genetic approach. Mice with floxed IGFIR gene $\left(\mathrm{IGF}^{\mathrm{fR}}{ }^{\mathrm{f} / \mathrm{f}}\right.$ mice) were injected in the barrel cortex with the virus AAV8-GFAP-Cre-mCherry (Fig. 3B, bottom images) or AAV8-GFAPmCherry as a control (Fig. $3 B$, top images) that included the Cre-recombinase under the astroglial promoter GFAP, and mCherry as a reporter. In $\mathrm{IGF}^{\mathrm{f}} \mathrm{f}^{\mathrm{ff}}$ mice injected with AAV8GFAP-Cre-mCherry, mCherry expression was largely reduced and confined to the soma (Fig. $2 F$, mCherry, IGF-IR ${ }^{-1}$ -) compared with the higher and more spread signal in control littermates (Fig.

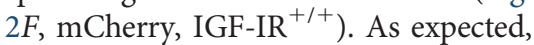
in the IGF-IR ${ }^{+/+}$mice, IGF-I elevated astrocyte calcium levels (frequency of calcium event: from $1.60 \pm 0.03$ basal to $2.93 \pm 0.05$ after IGF-I application; $p=$ 0.0054; Fig. 3C,H, IGF-IR ${ }^{+/+}$), inducing the LTD $_{\text {IGFI }}$ and increasing the PPR [percentage of peak amplitude: from $99.89 \pm 0.80 \%$ basal to $74.74 \pm 4.97 \%$ $\left.{ }^{*} p=0.0108\right)$ at $60 \mathrm{~min}$ after IGF-I application; percentage of PPR: from $100.00 \pm 2.64 \%$ basal to $120.92 \pm 1.31 \%$ at $60 \mathrm{~min}$ after IGF-I application; ${ }^{* *} p=$ 0.0034; Fig. $2 C, D$, IGF-IR ${ }^{+/+}$]. By contrast, in the IGF-IR ${ }^{-1-}$ mice, IGF-I did not modify the frequency of calcium elevations in astrocytes (frequency of calcium event: from $1.23 \pm 0.02$ basal to $1.04 \pm 0.004$ after IGF-I application; $p=$ 0.2128 ) or alter the IPSC amplitude and PPR [percentage of peak amplitude: from $100.27 \pm 1.55 \%$ to $107.16 \pm 5.62 \%$ $(p=0.3106)$; percentage of PPR: from $100.00 \pm 5.36 \%$ to $102.92 \pm 5.05 \%(p=$ $0.7014)$ basal and at $60 \mathrm{~min}$ after IGF-I application, respectively; Figs. $2 C, D, 3 D$, $\mathrm{IGF}^{-I R^{-1-}}$. These results further support the idea that LTD $_{\text {IGFI }}$ depends on IGF-IR activation in the astrocytes.

\section{LTD ${ }_{\text {IGFI }}$ requires $A_{2 A}$ adenosine but not mGluR receptor activation}

Astrocytic activation stimulates the release of glutamate that regulates synaptic transmission by acting on metabotropic glutamate receptors (mGluRs; Perea and Araque, 2007). We therefore checked whether the LTD $_{\text {IGFI }}$ is mediated by the activation of mGluRs. However, LTD IGFI $_{\text {was }}$ unaffected (percentage of peak amplitude: from $98.89 \pm 0.90 \%$ basal to $60.78 \pm 7.39 \%$ at $60 \mathrm{~min}$ after IGF-I application; Fig. $\left.2 C, \mathrm{MPEP}+\mathrm{LY},{ }^{* *} p=0.0022\right)$ by treatment with the antagonists of group I metabotropic glutamate receptors MPEP and LY367385, and the increase observed 
in the PPR induced by IGF-I was preserved (percentage of PPR: from $100.00 \pm 4.06 \%$ basal to $120.52 \pm 7.66 \%$ at 60 min after IGF-I application; Fig. $2 D$, $\left.\mathrm{MPEP}+\mathrm{LY},{ }^{*} p=0.024\right)$. Moreover, we observed that IGF-I evoked an increase in calcium event frequency in the presence of MPEP + LY367385 (frequency of calcium event: from $0.51 \pm 0.12$ basal to $1.07 \pm 0.14$ after IGF-I application; Fig. $\left.3 A, \mathrm{MPEP}+\mathrm{LY},{ }^{* *} p=0.0066\right)$. Although astrocytes are able to release glutamate, these data rule out the requirement of mGluR activation in the induction of LTD IGFI.

Astrocytes may also release ATP, which, after being converted to adenosine, may regulate synaptic transmission (Panatier et al., 2011; Araque et al., 2014). Therefore, we tested whether astrocytic ATP/Ado was responsible for the LTD $_{\text {IGFI. The }}$ LTD $_{\text {IGFI }}$ was abolished by the antagonist of adenosine $\mathrm{A}_{2 \mathrm{~A}}$ receptors, antagonist SCH 58261 (percentage of peak amplitude: from $100.02 \pm 0.63 \%$ basal to $94.98 \pm 2.43 \%$ at $60 \mathrm{~min}$ after IGF-I application; $p=0.0916$; Fig. $2 C$, $\mathrm{SCH})$, but not by the antagonist of adenosine A1 receptors CPT (percentage of peak amplitude: from $98.72 \pm 1.75 \%$ basal to $55.74 \pm 7.08 \%$ at $60 \mathrm{~min}$ after IGF-I application; ${ }^{* *} p=0.0008$; Fig. $2 C, \mathrm{CPT}$ ). Moreover, the increase in PPR induced by IGF-I was preserved in the presence of CPT but was absent in SCH 58261 [from $100.00 \pm 2.09$ to $99.76 \pm 1.85 \quad(p=$ $0.8967)$; percentage of PPR: from $100.00 \pm 5.90 \%$ to $118.42 \pm 4.95 \%\left({ }^{* *} p=\right.$ 0.0023 ) basal and at $60 \mathrm{~min}$ after IGF-I application in $\mathrm{SCH}$ and $\mathrm{CPT}$, respectively; Fig. 2D, SCH, CPT]. To test whether adenosine receptor activation occurs downstream of astrocytic calcium activity, we analyzed the effects of $A_{2 A}$ and $A_{1}$ receptor antagonists on astrocytic calcium signals. We observed that IGF-I still evoked an increase in calcium event frequency in the presence of $\mathrm{SCH}$ and CPT [frequency of calcium event: from $0.67 \pm 0.12$ to $1.40 \pm 0.17\left({ }^{\star} p=0.0194\right)$ and from $0.59 \pm 0.10$ to $1.20 \pm 0.13$ $\left.{ }^{* * *} p=0.0008\right)$ basal and after IGF-I application in $\mathrm{SCH}$ and CPT respectively; Fig. 3A, SCH, CPT]. Together, these results suggest that IGF-I stimulates the astrocytic release of ATP that induces LTD $_{\text {IGFI }}$ acting downstream of astrocytic calcium activity.

Therefore, we tested whether IGF-I was capable of stimulating the release of ATP from astrocytes. We used an ATP Assay Kit (see Materials and Methods) to monitor ATP levels in cultured astrocytes
A

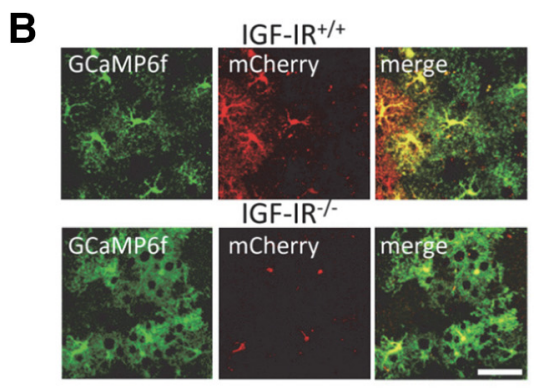

\section{C}
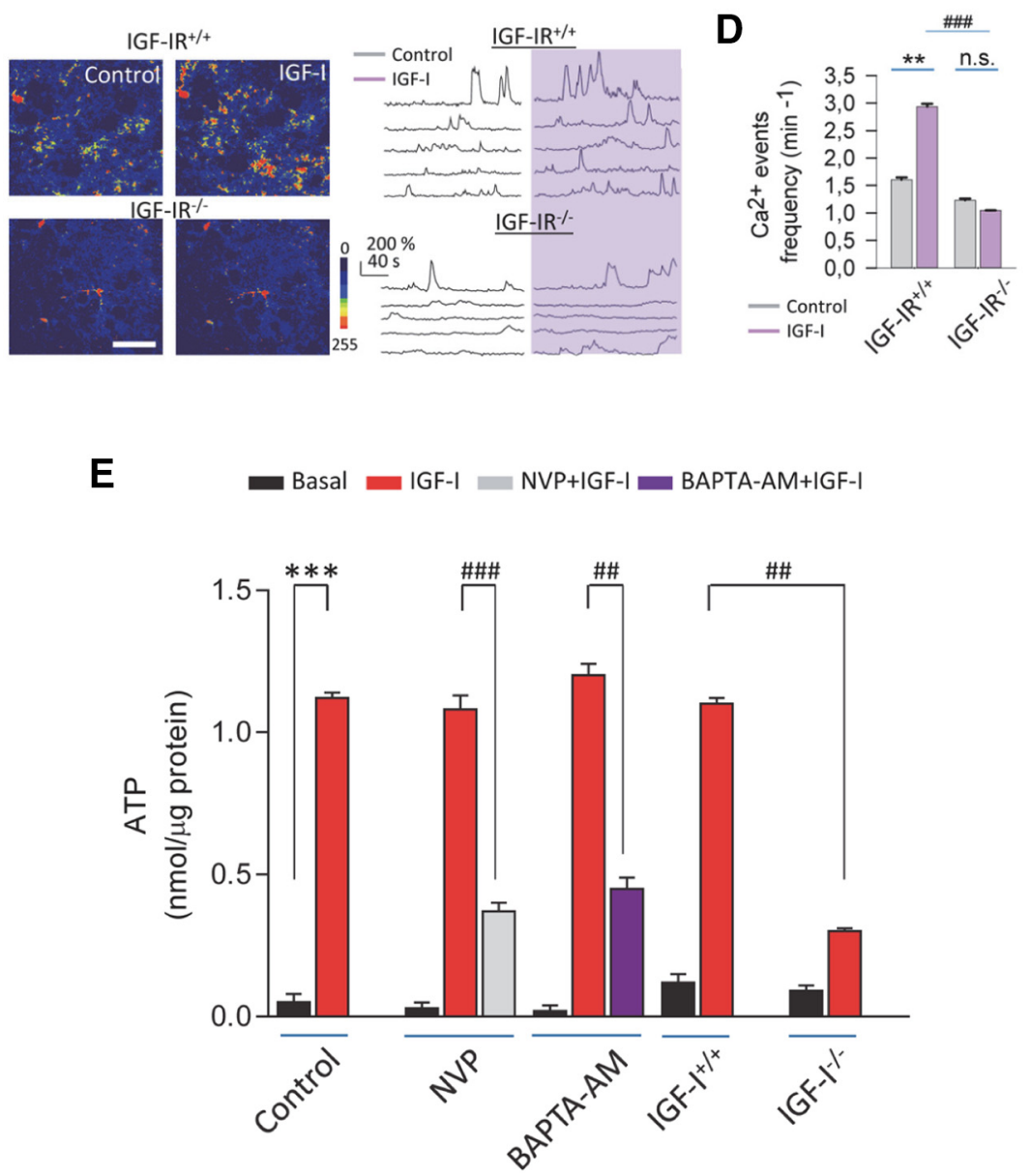

Figure 3. Astrocytic IGF-IR activation stimulates the calcium-dependent release of ATP. $\boldsymbol{A}$, Effect of IGF-I on the spontaneous $\mathrm{Ca}^{2+}$ event frequency of the astrocytes in different experimental conditions: in ACSF (control, $n=$ 55 astrocytes/4 animals; control vs IGF-I, $\left.{ }^{* *} p<0.01\right)$, NVP $(n=65$ astrocytes/3 animals; NVP vs NVP+IGF-I, $\mathrm{ns}), \mathrm{MPEP}+\mathrm{LY}\left(n=44\right.$ astrocytes/3 animals; MPEP $+\mathrm{LY}$ vs MPEP $\left.+\mathrm{LY}+\mathrm{IGF}-\mathrm{I},{ }^{* *} p<0.01\right), \mathrm{SCH}(n=48$ astrocytes/4 animals; SCH vs SCH+IGF-I, $\left.{ }^{*} p<0.05\right)$, and CPT $(n=72$ astrocytes/2 animals; CPT vs CPT+IGF-I, ${ }^{* * *} p<0.001$, two-tailed Student's paired $t$ test). $\boldsymbol{B}$, Representative images of locally targeting astrocytes with GFAP-GCaMP6f-mCherry for IGF-IR ${ }^{+/+}$(top images) and GFAP-GCaMP6f-mCherry-CRE for IGF-IR ${ }^{-/-}$(bottom images). Scale bar, $50 \mu \mathrm{m}$. C, Pseudocolor $\mathrm{Ca}^{2+}$ images showing the intensities of GCaMP6f-expressing astrocytes in the barrel cortex, in the basal condition and during IGF-I exposure in IGF-IR ${ }^{+/+}$(top images) and IGF$\mathrm{IR}^{-1-}$ astrocytes (bottom images). Scale bar, $50 \mu \mathrm{m}$. Right, Representative $\mathrm{Ca}^{2+}$ traces in the astrocytes from $I G F-I R^{+/+}$(top traces) and the IGF-IR ${ }^{-I-}$ astrocytes (bottom traces). D, Spontaneous $\mathrm{Ca}^{2+}$ event frequency in the processes of the astrocytes in the basal condition and during IGF-I exposure in IGF-IR ${ }^{+I+}(n=135$ astrocytes/2 animals; control vs IGF-I, $\left.{ }^{* *} p<0.01\right)$ and IGF-IR ${ }^{-/-}(n=67$ astrocytes/2 animals; control vs IGF-I, ns, two-tailed Student's paired $t$ test) astrocytes. $\boldsymbol{E}$, Bar plot of ATP concentration in a culture of astrocytes before (black bar) and during IGF-I exposure (red bar) in different experimental conditions: ACSF ( $n=6$; basal vs IGF-I, $\left.{ }^{* * *} p<0.001\right)$, NVP $\left(n=6\right.$; IGF-I vs NVP+IGF-I, $\left.{ }^{* * *} p<0.001\right)$, BAPTA-AM $(n=6$; IGF-I vs BAPTA-AM + IGF-I, $\left.{ }^{* *} p<0.01\right)$, and in the astrocytes from the IGF-IR ${ }^{+/+}$and IGF-IR ${ }^{-1-}$ mice $\left(n=6 ; \mathrm{IGF}^{-I^{+/+}} \mathrm{vs} \mathrm{IGF-I}^{-1-}\right.$, ${ }^{* *} p<0.01$, two-way ANOVA with post hoc Bonferroni multiple-comparisons test). ns, not significant, ${ }^{\#} p<$ $0.01,{ }^{\# \#} p<0.001$. 


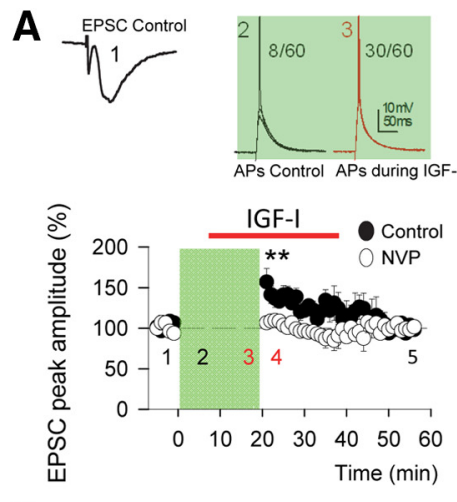

C
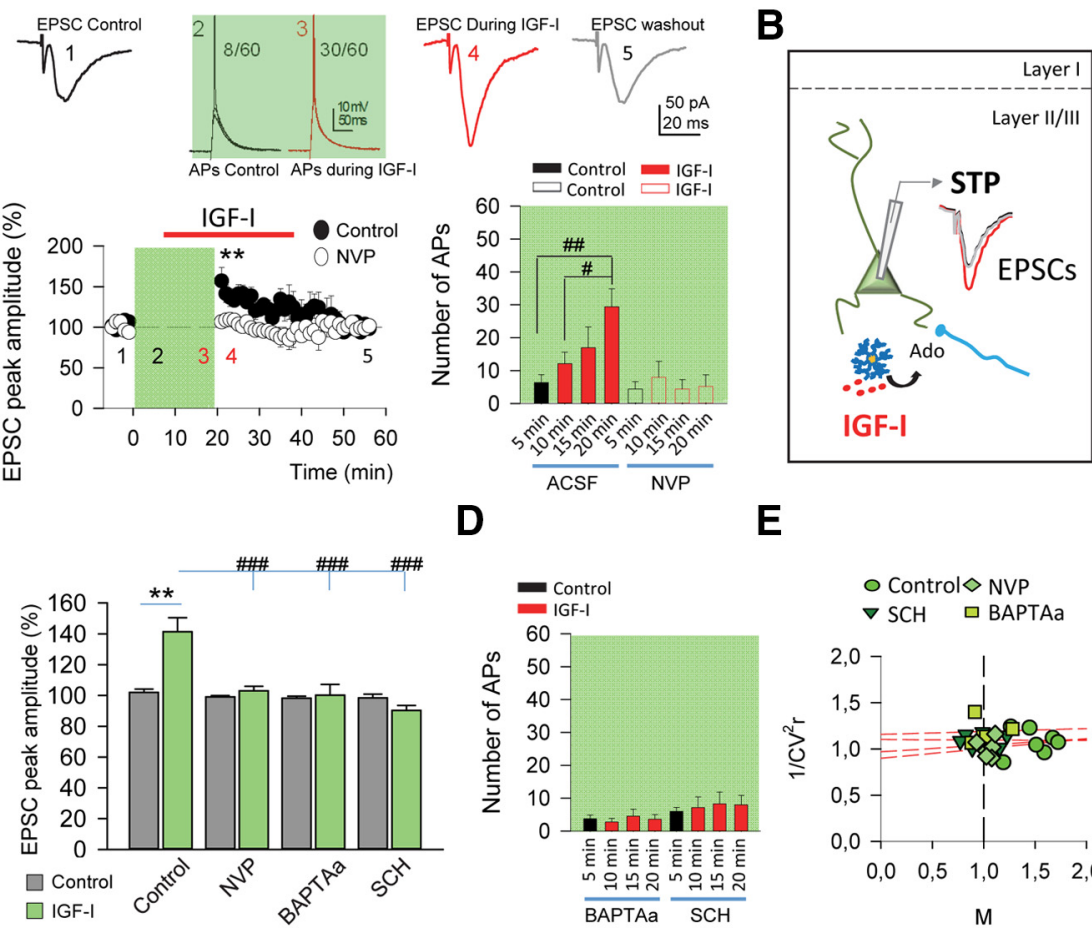

D

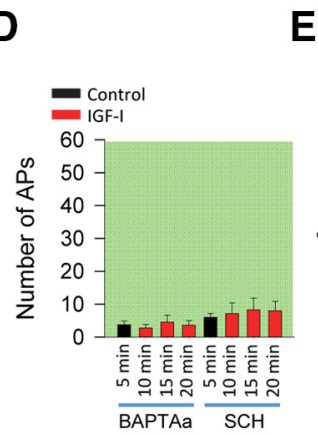

E

Figure 4. IGF-I generates a transient potentiation of the EPSCS. A, Top, Representative EPSC responses before [black, (1)], during IGF-I [red, (4)], and during IGF-I washout [gray, (5)]. IGF-I increases the number of AP responses recorded every 60 stimuli (green box), from 8 before IGF-I [black trace, (2)] to 30 during IGF-I [red trace, (3)]. Bottom, Left, Time course of the EPSC peak amplitude before, during IGF-I, and during IGF-I washout in ACSF (full circles), and in the presence of NVP-AEW 541 (empty circles). Note that during the green box, EPSC peak amplitude values are missed because we recorded the effect of IGFI on the number of stimuli evoking AP responses. Right, Number of APs recorded every 5 min before (black) and during IGF-I (red) in ACSF (filled bars; $n=8$ cells/3 animals; control vs IGF-I, \#p $<0.05$, \#\# $<0.01 ; F_{(3,28)}=5.474$ ) and in NVP (empty bars; $n=5$ cells $/ 2$ animals; NVP vs NVP+IGF-I, ns; $F_{(3,16)}=0.2402$, one-way ANOVA). $B$, Cartoon showing that the STP of the EPSCS induced by IGF-I depends on the IGF-IR activation on astrocytes and the adenosine receptor-mediated increase of the release of glutamate from the glutamatergic terminal (blue terminal). C, Effect of IGF-I on the EPSC peak amplitude (green bar), as a percentage of the control (gray bar), in different experimental conditions: ACSF, NVP, BAPTAa ( $n=5$ cells $/ 3$ animals; control vs IGF-I, ns), and SCH ( $n=6$ cells/3 animals; SCH vs SCH+IGF-I, ns, two-tailed Student's paired $t$ test). Note that the modulation of the EPSCS by IGF-I is prevented in the same conditions in which the modulation of the IPSCS by IGF-I was abolished. $\boldsymbol{D}$, As in $\boldsymbol{A}$, right bottom, but in BAPTA-loaded astrocyte ( $n=5$ cells $/ 3$ animals; control vs IGF-I, ns; $\left.F_{(3,16)}=0.2457\right)$ and $\mathrm{SCH}\left(n=6\right.$ cells/3 animals; SCH vs SCH + IGF-I, ns; $\left.F_{(3,20)}=0.1302\right)$. One-way ANOVA. $\boldsymbol{E}$, Plot of the variance $\left(1 / \mathrm{CV}^{2} \mathrm{r}\right)$ as a function of the mean EPSC peak amplitude (M) in the control, BAPTA-loaded astrocyte, and SCH. Note that the control condition does not follow a diagonal, suggesting a postsynaptic origin of the transient potentiation. ns, not significant, ${ }^{* *} p<0.01$.

before and after $1 \mathrm{~h}$ of treatment with IGF-I (10 nM). We found that IGF-I elevated the extracellular levels of ATP $(1.1 \pm 0.04$ $\mathrm{nmol} / \mu$ g; Fig. $3 E$, control, ${ }^{* * *} p<0.001$ ), an effect that was prevented when cultures where simultaneously treated with NVP $(0.25 \pm 0.05 \mathrm{nmol} / \mu \mathrm{g}$; Fig. $3 E, \mathrm{NVP})$. Furthermore, the IGF-Iinduced release of ATP was absent when astrocyte calcium signaling was prevented by treating cultures with BAPTA-AM $(0.45$ $\pm 0.04 \mathrm{nmol} / \mu \mathrm{g}$; Fig. $3 E$, BAPTA-AM). Moreover, ATP was not released when astrocytes were obtained from mice lacking IGF-IR. $\left(1.1 \pm 0.02\right.$ and $0.3 \pm 0.01 \mathrm{nmol} / \mu \mathrm{g}$ in IGF-IR ${ }^{+/+}$and $\mathrm{IGF}^{-\mathrm{IR}^{-/}-}$, respectively; Fig. $3 E$, IGF-IR ${ }^{-1-}$, IGF-IR ${ }^{+/+}$). These data suggest that IGF-I, acting through the IGF-IR in astrocytes, stimulates the calcium-dependent release of ATP, which leads to the activation of $A_{2 \mathrm{~A}}$ receptors, thus inducing $L T D_{\mathrm{IGFI}}$.

\section{IGF-IR activation induces a short-term potentiation of the EPSCs}

The next step was to analyze whether IGF-I could also modulate the efficacy of excitatory synaptic transmission. To measure the effect of IGFI in excitatory synaptic transmission when the

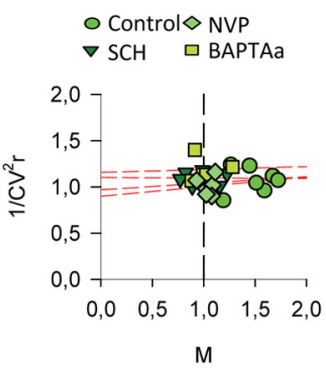

inhibition is present, we repeated the experiment illustrated in Figure $1 B$, but instead of recording the PSPs, we recorded the EPSCs at the reversal potential of the inhibitory synaptic transmission $(-70 \mathrm{mV})$. In these experiments, as in Figure $1 B$, IGF-I still increased the number of synaptic stimuli that evoked APs (number of APs: from $8.0 \pm 2.5$ basal to $30.5 \pm 4.8$ at $15 \mathrm{~min}$ after IGF-I application; Fig. $4 A$, \#\# = $0.0044)$. Moreover, IGF-I induced a significant short-term potentiation (STP) of the ESPCs (termed STP IGF-I; percentage of peak amplitude: from $102.00 \pm$ $2.16 \%$ basal to $141.32 \pm 9.10 \%$ at $20 \mathrm{~min}$ after IGF-I application; ${ }^{\star *} p=0.0011$; Fig. $4 A, B)$. This effect was prevented by the IGF-IR selective inhibitor NVPAEW 541 [number of APs: from $4.4 \pm 2.3$ basal to $5.2 \pm 3.5$ at $15 \mathrm{~min}$ after IGF-I application $(p=0.1806)$; percentage of peak amplitude: from $99.10 \pm 0.79 \%$ basal to $103.0 \pm 3.02 \%$ at $20 \mathrm{~min}$ after IGF-I application; $p=$ 0.2338; Fig. $4 A, C$ ). Since an increase in cytosolic $\mathrm{Ca}^{2+}$ in astrocytes is required for the induction of LTD IGFI (see above), we explored whether the induction of $\mathrm{STP}_{\mathrm{IGFI}}$ also depended on the activation of astrocytes. After BAPTA loading into the astrocytic network, IGF-I was not able to modulate the EPSCs (percentage of peak amplitude: from $95.10 \pm 1.46 \%$ basal to $108.21 \pm 10.51 \%$ at $20 \mathrm{~min}$ after IGF-I application; $p=0.2571$; Fig. $4 C$, BAPTAa). These results confirm that the STP $_{\text {IGFI }}$ not only depends on IGF-IR activation in astrocytes, but also on calcium elevations in their cytosol.

We then checked whether the potentiation of EPSCs by IGF-I requires ATP released by astrocytes. The EPSC modulation by IGF-I was abolished by the $\mathrm{A}_{2 \mathrm{~A}}$ receptor antagonist $\mathrm{SCH}$ (percentage of peak amplitude: from $98.42 \pm 2.41 \%$ in basal to $90.20 \pm 3.36 \%$ at 20 min after IGF-I application; $p=$ 0.2084; Fig. $4 C, \mathrm{SCH}$ ). In addition, IGF-I did not increase the number of APs during SCH or when BAPTA was loaded into the astrocytic network [number of APs: from $3.8 \pm 1.1$ to $3.6 \pm 1.4(p=0.9941)$ basal and from $6.0 \pm 1.2$ to $8.0 \pm 2.9(p$ $=0.994)$ at $15 \mathrm{~min}$ after IGF-I application in BAPTAa and $\mathrm{SCH}$, respectively; Fig. $4 D$ ]. To test the presynaptic or postsynaptic origin of the effect of IGF-I on the EPSCs, we constructed $1 / \mathrm{CV}^{2}$ plots (see experimental procedures). We observed that the increase in the mean EPSC peak amplitude was not paralleled by an increase in the $1 / \mathrm{CV}^{2}$ parameter, which suggests a postsynaptic origin of the EPSC potentiation $\left(R^{2}=0.0107\right.$; Fig. $4 E$, control). These data suggest that potentiation of the EPSCs induced by IGF-I was mediated by a postsynaptic mechanism that was absent in the recordings under BAPTA in astrocytes (Fig. 4E). These combined results indicate that IGF-I induces an increase in calcium levels in astrocytes, which leads to the activation of $A_{2 A}$ 
A
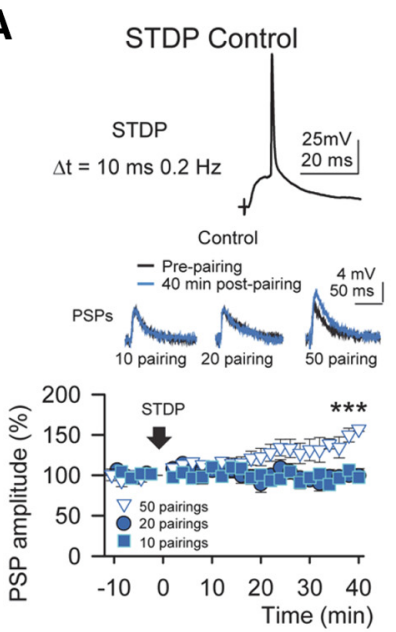

D

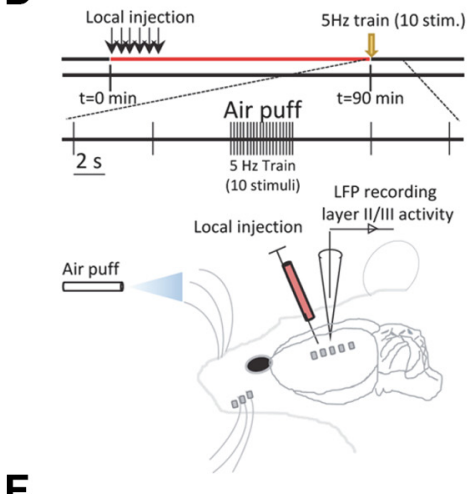

$\mathbf{F}$

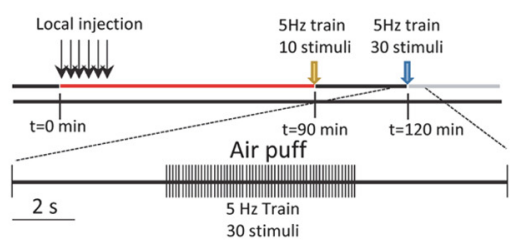

G

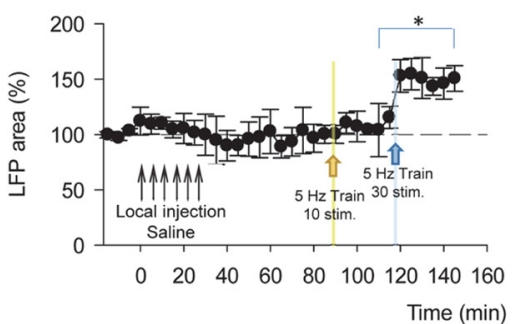

H

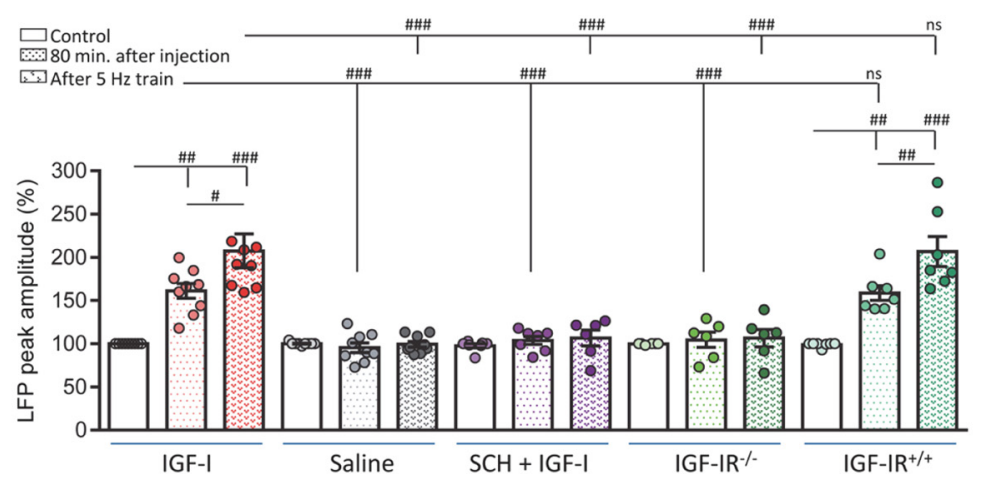

Figure 5. IGF-I favors Hebbian LTP ex vivo and in vivo. A, Top, Representative PSP followed by an AP with a $10 \mathrm{~ms}$ delay and a frequency of $0.2 \mathrm{~Hz}$. Bottom, top, Representative PSPs in the control and $40 \mathrm{~min}$ after 10, 20, and 50 pairings for the STDP induction. Bottom, bottom, Time course of the PSPs with 10 pairings ( $n=5$ cells $/ 2$ animals basal vs after $40 \mathrm{~min}$ of STDP, ns), with 20 pairings ( $n=6$ cells/3 animals; basal vs after $40 \mathrm{~min}$ of STDP, ns), and with 50 pairings ( $n=7$ cells $/ 3$ animals; basal vs after 40 min of STDP, ${ }^{* * *} p<0.001$ ) for the STDP induction (black arrow). Two-tailed Student's paired $t$ test. $\boldsymbol{B}$, Top, Time course scheme showing the IGF-I exposure, washout, and STDP induction (black arrow). Bottom, top, Representative PSPs in the control and 40 min after 10, 20, and 50 pairings for the STDP induction after IGF-I exposure and washout. Bottom, bottom, Time course of the PSPs with 10 pairings ( $n=5$ cells $/ 2$ animals; basal vs after IGF-I, ns), 20 pairings ( $n=6$ cells/2 animals; basal vs after IGF-I, ${ }^{* *} p<0.001$ ), and 50 pairings $(n=6$ cells $/ 3$ animals; basal vs after IGF-I,

receptors, thus inducing a postsynaptic STP of the EPSCs and a presynaptic LTD of the IPSCs, which would result in the LTP of the PSPs.

$\left.{ }^{* * *} p<0.001\right)$ for the STDP induction (black arrow) after IGF-I exposure and washout. Two-tailed Student's paired $t$ test. C, Cartoon showing that IGF-I exposure induces an LTP of the PSPs (LTP IGFI) that increases the magnitude of LTP by STDP and facilitates its induction. $\boldsymbol{D}$, Top, Scheme showing the time course of local injection (arrows) and whisker stimulation [5 Hz, 10 stimuli (stim.), blue arrow] used in the in vivo experiments. Bottom, Drawing to illustrate the recording electrode and Hamilton syringe location, and air puff stimulation in the anesthetized mouse. $\boldsymbol{E}$, Top, Representative LFPs in the control [black, (1)], after 80 min IGF-I and saline injections in the wild-type mouse [dark gray, (2)], and after $5 \mathrm{~Hz}$ train whisker stimulation [gray, (3)]. Bottom, Time course of LFP area with IGF-I injection (arrows) in the wild-type mouse (red triangle; $n=10$ animals; basal vs after 80 min injection, \#\#p $<0.01$; basal vs after $5 \mathrm{~Hz}$ train, \#\#\# $<0.001$; after 80 min injection vs after $5 \mathrm{~Hz}$ train, \#\#p $\left.<0.01 ; F_{(2,26)}=20.65\right)$, previously intraperitoneally injected $\mathrm{SCH}(2 \mathrm{mg} / \mathrm{kg}$; purple square; $n=7$ animals; basal vs after $80 \mathrm{~min}$ injection, ns; basal vs after $5 \mathrm{~Hz}$ train, ns; after 80 min injection vs after $5 \mathrm{HZ}$ train, ns; nonparametric test; $H=1.983$ ), IGF-IR ${ }^{-1-}$ (green diamond; $n=6$ animals; basal vs after 80 min injection, ns; basal vs after $5 \mathrm{~Hz}$ train, ns; after 80 min injection vs after $5 \mathrm{HZ}$ train, ns; nonparametric test; $H=0.3702$ ), IGF-IR ${ }^{+/+}$(dark green triangle; $n=7$ animals; basal vs after 80 min injection, $\# \# p<0.01$; basal vs after $5 \mathrm{~Hz}$ train, \#\#p $<0.001$; after 80 min injection vs after $5 \mathrm{~Hz}$ train, \#\#p $<0.01 ; F_{(2,18)}=$ 27.94), and saline injection (black circle; $n=9$ animals; basal vs after 80 min injection, ns; basal vs after $5 \mathrm{~Hz}$ train, ns; after $80 \mathrm{~min}$ injection vs after $5 \mathrm{~Hz}$ train, $\mathrm{ns} ; F_{(2,23)}=1.766$ ). One-way ANOVA. $\boldsymbol{F}$, Scheme showing the time course of the saline local injection (arrows) and the following $5 \mathrm{~Hz}$ train whisker stimulations. G, Time course of LFP area with IGF-I injection (arrows) in the wild-type mice with local saline injection (black arrows) and 10 (yellow arrow) and 30 (blue arrow) stimuli trains whisker stimulation at $5 \mathrm{~Hz}$. Note that 30 stimuli induced the LTP of the LFP but 10 stimuli did not change the LFP amplitude ( $n=7$ animals; 10 stimuli train vs 30 stimuli train, $\left.{ }^{*} p<0.05\right)$. $\boldsymbol{H}$, LFP amplitude in the control, $80 \mathrm{~min}$ after injections, and after $5 \mathrm{~Hz}$ train whisker stimulation in different experimental conditions: the wildtype mice with IGF-I injection (red; $n=10$ animals; basal vs after 80 min injection, \#\#p $<0.01$; basal vs after $5 \mathrm{~Hz}$ train, $\# \#$ \# $<0.001$; after 80 min injection vs after $5 \mathrm{~Hz}$ train, $\# p<0.05 ; F_{(2,24)}=18.97$ ), saline injection (gray; $n=9$ animals; basal vs after 80 min injection, ns; basal vs after $5 \mathrm{~Hz}$ train, ns; after $80 \mathrm{~min}$ injection vs after $5 \mathrm{~Hz}$ train, ns; $\left.F_{(2,24)}=0.4747\right)$, previous intraperitoneally injected $\mathrm{SCH}$ (purple; $n=7$ animals; basal vs after 80 min injection, ns; basal vs after $5 \mathrm{~Hz}$ train, ns; after 80 min injection vs after $5 \mathrm{~Hz}$ train, $\mathrm{ns}$; nonparametric test; $\mathrm{H}=1.967$ ), and the IGF-IR ${ }^{-1-}$ mice (green; $n=6$ animals; basal vs after $80 \mathrm{~min}$ injection, ns; basal vs after $5 \mathrm{~Hz}$ train, ns; after 80 min injection vs after $5 \mathrm{~Hz}$ train, ns; nonparametric test, $H=0.3702$ ), and its littermates the IGF-IR ${ }^{+/+}$mice (dark green; $n=7$ animals; basal vs after 80 min injection, $\# \# p<0.01$; basal vs after $5 \mathrm{~Hz}$ train, \#\#p $<0.001$; after 80 min injection vs after $5 \mathrm{~Hz}$ train, \#\# $<0.01 ; F_{(2,18)}=$ 23.35, one-way ANOVA). 


\section{IGF-I controls the induction threshold of Hebbian LTP $\left(\mathrm{LTP}_{\mathbf{H}}\right)$}

Because IGF-I induces the LTP of the PSPs, it may have a key role in the modulation of Hebbian LTP $\left(\mathrm{LTP}_{\mathrm{H}}\right)$, decreasing its induction threshold. Therefore, we tested the impact of IGF-I on the $\mathrm{LTP}_{\mathrm{H}}$ induced by spike timing-dependent plasticity (STDP). First, we analyzed the $\mathrm{LTP}_{\mathrm{H}}$ induction threshold under the control conditions. We used STDP protocols consisting of a subthreshold PSP followed by a backpropagating AP at delays of $10 \mathrm{~ms}$ repeated 10,20 , and 50 times at $0.2 \mathrm{~Hz}$. While 10 and 20 pairings were unable to induce the $\mathrm{LTP}_{\mathrm{H}}$ of the PSPs [percentage of peak amplitude: from $99.89 \pm 0.21 \%$ to $100.03 \pm 4.17 \%$ basal $(p=0.9758)$; from $101.88 \pm 0.71 \%$ to $101.51 \pm 2.79 \%$ ( $p=$ 0.8339 ) at $40 \mathrm{~min}$ after 10 and 20 pairings, respectively; Fig. $5 \mathrm{~A}$, blue squares and circles, respectively], 50 pairings induced a robust LTP of PSPs (percentage of peak amplitude: from $96.01 \pm 4.12 \%$ basal to $137.62 \pm 8.33 \%$ at $40 \mathrm{~min}$ after 50 pairings; Fig. $5 A$, white triangles, $\left.{ }^{* *} p=0.0007\right)$. We then performed similar experiments but in slices in which IGF-I had been bath applied previously. We allowed $25 \mathrm{~min}$ of IGF-I washout and a pyramidal neuron was "patched" and the number of pairings required to induce $\mathrm{LTP}_{\mathrm{H}}$ by STDP was tested. In these experiments, repeating 10 pairings was unable to induce the $\mathrm{LTP}_{\mathrm{H}}$ of the PSPs (percentage of peak amplitude: from $99.39 \pm 1.46 \%$ basal to $99.79 \pm 3.88 \%$ at 40 min after 10 pairings; $p=0.9271$; Fig. $5 B$, red squares). However, 20 and 50 pairings induced a robust LTP $_{\mathrm{H}}$ of PSPs [percentage of peak amplitude: from $99.36 \pm$ $1.08 \%$ to $141.59 \pm 4.38 \% \quad\left({ }^{* * *} p=0.00008\right)$ basal; from $99.36 \pm 0.89 \%$ to $169.13 \pm 6.36 \%\left({ }^{* *} p=0.0001\right)$ at $40 \mathrm{~min}$ after 20 and 50 pairings, respectively; Fig. $5 B$, red circles, white triangles). These results suggest that these pyramidal neurons had been facilitated by IGF-I, showing a reduction of the induction threshold of the $\operatorname{LTP}_{\mathrm{H}}$ (Fig. $5 C$ ).

Repetitive whisker stimulation at the frequency used to explore the environment $(5 \mathrm{~Hz})$ induces a long-lasting increase in synaptic efficacy at layer II/III neurons depending on the activation of NMDA receptors (Barros-Zulaica et al., 2014). To test for a similar reduction in the $\mathrm{LTP}_{\mathrm{H}}$ induction threshold in vivo, we analyzed the effect of IGFI on this NMDAR-dependent LTP induced by repetitive stimulation of the vibrissae (Fig. $5 D$ ). In the control conditions using saline injections, 30 stimuli of the vibrissae at $5 \mathrm{~Hz}$ stimulation induced an LTP of the LFP $\left(150.83 \pm 12.20 \%\right.$ of LFP area at baseline; Fig. $\left.5 F, G,{ }^{*} p=0.0248\right)$, whereas 10 stimuli at $5 \mathrm{~Hz}$ train was not sufficient to modulate the LFP (percentage of LFP area: from $99.94 \pm 0.33 \%$ basal to $101.76 \pm 8.01 \%$ at $30 \mathrm{~min}$ after $5 \mathrm{~Hz}$ train $(p=0.5055)$; percentage of LFP amplitude: from $100.16 \pm 0.57$ basal to $99.29 \pm 3.34 \%$ $(p=0.8699)$ at $30 \mathrm{~min}$ after $5 \mathrm{~Hz}$ train; Fig. $5 E, G)$. However, 10 stimuli at $5 \mathrm{~Hz}$ induced an LTP of the LFP [percentage of LFP area: from $99.45 \pm 1.80 \%$ basal to $201.66 \pm 23.49 \%$ (\#\#\# $<$ 0.0001 ) at $30 \mathrm{~min}$ after $5 \mathrm{~Hz}$ train; percentage of LFP amplitude: from $99.41 \pm 0.55 \%$ basal to $223.53 \pm 22.56 \%(\# \# p<0.0001)$ at $30 \mathrm{~min}$ after $5 \mathrm{~Hz}$ train; Fig. $5 E, H$, IGF-I] in mice in which LTP $_{\text {IGFI }}$ was previously induced by intracranial IGF-I injection (see above; Fig. 1C,D). This reduction in the threshold of induction of LTP was abolished when IGF-I was applied to mice in which the $\mathrm{A}_{2 \mathrm{~A}}$ adenosine receptor antagonist $\mathrm{SCH}$ had previously been intraperitoneally injected [percentage of LFP area: from $92.82 \pm 1.21 \%$ basal to $96.74 \pm 10.34 \%(p=0.6545)$ at $30 \mathrm{~min}$ after $5 \mathrm{~Hz}$ train; percentage of LFP amplitude: from $97.61 \pm 2.39 \%$ basal to $106.62 \pm 9.12 \%(p=0.5076)$ at $30 \mathrm{~min}$ after $5 \mathrm{~Hz}$ train; Fig. $5 E, H, \mathrm{SCH}+\mathrm{IGF}-\mathrm{I}]$ or when IGF-I was applied to the mice in which IGF-IR had been removed

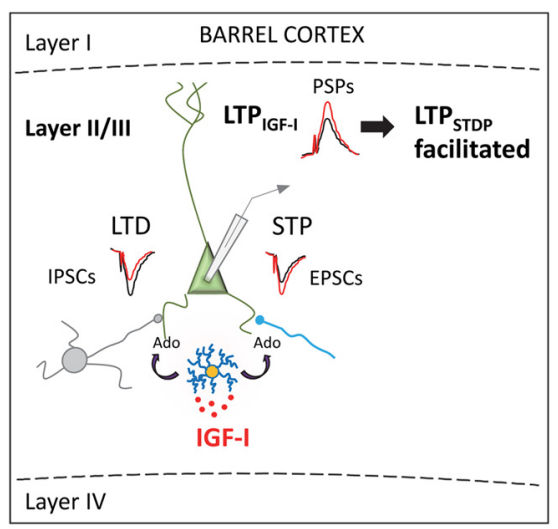

Figure 6. Model showing the actions of IGF-I. Schematic diagram showing, from bottom to the top, that the activation of layer II/III astrocytes (1; orange cell in the bottom) by IGF-I (red circles) promotes the release of ATP/Ado (2). Ado acts on both the excitatory (3; blue) and inhibitory (3; gray) synapses inducing STP of the EPSCS (4), and LTD of the IPSCS (5), respectively (black and red superimposed responses are those recorded before and during the application of IGF-I). The net effect of this synaptic modulation is the LTP ${ }_{|G F|}$, an LTP of the PSP recorded from the soma of the layer II/III pyramidal neuron. The LTP IGFI facilitates the induction of the Hebbian LTP by STDP protocols and increases its magnitude.

specifically from astrocytes [percentage of LFP area: from $101.51 \pm 2.05 \%$ basal to $91.48 \pm 11.85 \%(p=0.9999)$ at $30 \mathrm{~min}$ after $5 \mathrm{~Hz}$ train; percentage of LFP amplitude: from $99.68 \pm 0.31 \%$ basal to $106.40 \pm 10.15 \%(p=0.8977)$ at $30 \mathrm{~min}$ after $5 \mathrm{~Hz}$ train in IGF-IR ${ }^{-1-}$ mice]. Interestingly, we observed an LTP of the LFP [percentage of LFP area: from $99.64 \pm 0.43 \%$ basal to $241.08 \pm 15.07 \%\left({ }^{* *} p<0.0001\right)$ at $30 \mathrm{~min}$ after $5 \mathrm{~Hz}$ train; percentage of LFP amplitude: from $98.89 \pm 1.02 \%$ basal to $206.60 \pm 17.31 \%\left({ }^{* *} p<0.0001\right)$ at $30 \mathrm{~min}$ after $5 \mathrm{~Hz}$ train in $\mathrm{IGF}^{-\mathrm{IR}^{+/+}}$mice; Fig. $5 E, H, \mathrm{IGF}^{-\mathrm{IR}^{-/-}}$, IGF-IR $\left.{ }^{+/+}\right]$. Therefore, these results indicate that IGF-I favors the induction of a LTP by reducing the threshold of its induction both ex vivo and in vivo (Fig. 6).

\section{The performance of a whisker discrimination task is impaired in the astrocyte-specific IGF-IR ${ }^{-1-}$ mice}

Finally, we tested whether the activation of IGF-IR on astrocytes is involved in the performance of a dependent discrimination task. We used a test based on the ability of the mice to discriminate different textures in the arms of a Y-maze (Fig. 6B). We compared the ability to perform this task on the astrocyte-specific IGF-IR ${ }^{-1-}$ mice (Fig. $7 A, \# \# p<0.01$ ) with their control littermates (IGF-I ${ }^{+/+}$mice). No differences were observed between the IGF-IR ${ }^{-1-}$ mice and their control littermates in the number of visits to the arms $(p=0.1142$; Fig. $7 B)$, indicating normal deambulatory activity. Interestingly, the IGF-IR ${ }^{-1}-$ mice spent less time examining the arm with the novel texture (Fig. $7 C$, left, $\# p=0.0336$ ), indicating impaired texture discrimination (Fig. $7 C$, right, $\# \# p=0.0059$ ). Conversely, whisker perception in the IGF-IR ${ }^{-1-}$ mice was preserved, as indicated by their normal performance in the gap-crossing test ( $p=0.6199$; Fig. $7 D$, left). In addition, the working memory was also normal in the IGF-IR ${ }^{-/-}$mice, as indicated by preserved performance in the $\mathrm{Y}$-maze alternation test ( $p=0.7474$; Fig. $7 D$, right). Together, these results indicate that the activation of IGF-IR on astrocytes increases the performance of the texture discrimination in mice, which suggests a crucial role in the learning and memory processes dependent on the barrel cortex activity. 


\section{Discussion}

The data in this study challenge the standard view that astrocytes play a key role in the induction of LTP or LTD, mainly on excitatory synapses in cortical circuits, and expand the view of the IGF-I action in the brain. Instead, we now provide conclusive evidence that astrocytes are mandatory intermediates for the LTD of inhibitory synapses in the barrel cortex, which relies on astrocytic release of ATP as a result of the IGF-IR activation. Although the observation that IGF-I action on the brain is crucial for learning and memory is well known, here we are proposing a reinterpretation of the classical IGF-I mechanism, from the IGF-I activation of neurons to its action on astrocytes. Therefore, the results presented in this study support the initial hypothesis that astrocytic IGF-IR is a key player in the IGF-I action related to learning and memory.

The inhibitory transmission controls the operation of cortical circuits, and the modulation of synaptic inhibition plays an important role in the induction of cortical plasticity. Our results show that IGF-I induces a long-lasting depression of the IPSCs that would result in an LTP of the PSPs that we have termed LTP IGFI. Moreover, we further analyzed how IGF-IR activation is able to favor the induction of NMDAR-dependent LTP and improves the performance of the texture discrimination in mice. We have shown that the activation of IGF-IRs in astrocytes triggers the calcium-dependent release of $\mathrm{ATP} / \mathrm{Ado}$, and the activation of $\mathrm{A}_{2 \mathrm{~A}}$ adenosine receptors results in the $\mathrm{LTD}_{\mathrm{IGFI}}$ by decreasing the probability of GABA release at the inhibitory terminals (Fig. $2 B$, mechanistic diagram). In addition, the ATP/Ado also induced a short-term increase in the efficacy of the excitatory synaptic transmission. The lack of LTD $_{\text {IGFI }}$ in mice in which IGF-IR has been selectively ablated in astrocytes suggests that IGF-IR activation in astrocytes is crucial to the induction of this novel form of long-lasting downregulation of cortical synaptic inhibition.

IGF-I elicits a long-lasting depression of GABA release by cerebellar Purkinje cells in response to glutamate, indicating that IGF-I may act as a modulator of glutamatergic transmission in the adult rat olivocerebellar system (Castro-Alamancos and Torres-Aleman, 1993; Castro-Alamancos et al., 1996). Also, IGF-I has been shown to modulate GABAergic transmission in the olfactory bulb (Liu et al., 2017). However, this is the first time that an IGF-Imediated long-lasting depression of fast GABAergic synaptic transmission in the neocortex been described. We have demonstrated that IGF-I induces the release of ATP from cortical astrocytes that generates the long-lasting depression of GABA release. Although IGF-IRs may be present in the inhibitory GABAergic terminals, there are no clear data showing a direct action of IGF-I acting on presynaptic IGF-IRs.
A

Astrocyte-specific

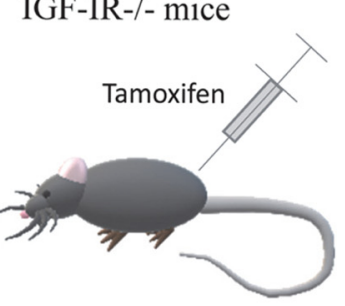

B

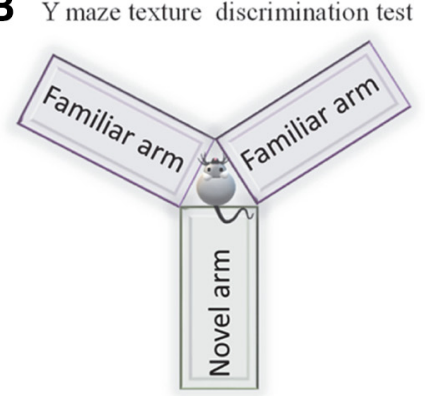

\section{Brain levels of IGF-IR mRNA}

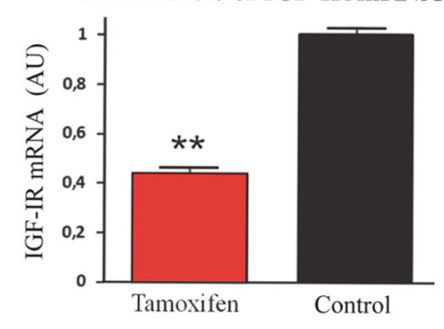

Deambulatory activity

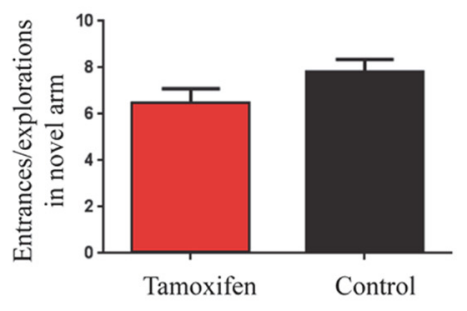

C

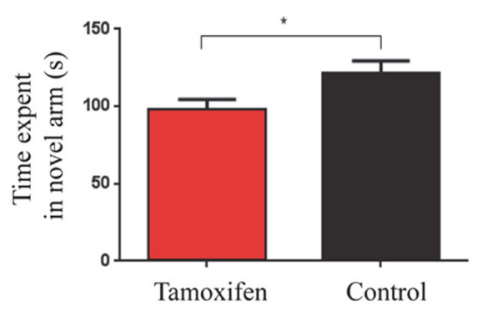

$\mathbf{D}$ Sensory perception
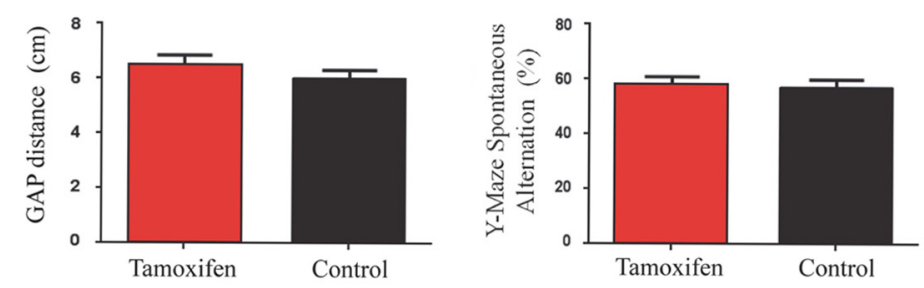

Figure 7. The performance of a whisker-based discrimination task is impaired in the astrocyte-specific IGF-IR ${ }^{-1-}$ mice. $\boldsymbol{A}$, Left, Schema of the transgenic mice generation with tamoxifen-regulated deletion of IGF-IR in astrocytes (IGF-IR ${ }^{-1-}$ mice). Right, The brain levels of IGF-IR mRNA, as determined by quantitative PCR, are reduced in the $I G F-I R^{-1-}$ mice after tamoxifen injection, when compared with the vehicle-injected control mice $(n=5$ animals injected with tamoxifen vs control, $\left.{ }^{* *} p<0.01\right)$. B, Left, Schema of Y-maze whisker-dependent texture discrimination test. Two arms (familiar) were covered with 500 grit sandpaper, and the third (novel) was covered with 220 grit sandpaper. Because the three arms of the maze are identical and there are no extramaze cues, discrimination of novelty versus familiarity relies only on the different textures that the mice can perceive with their whiskers. Right, IGF-IR ${ }^{-1-}$ and the control mice show no difference in their entrance to the different arms ( $n=13$ animals; tamoxifen vs control, ns; twoway ANOVA with post hoc Bonferroni multiple-comparisons test. $C$, Left, However, the control mice spent more time exploring the novel arm (220 grit sandpaper) than the IGF-IR ${ }^{-/-}$mice $\left(n=13\right.$ animals; tamoxifen vs control, $\left.{ }^{*} p<0.05\right)$. Right, The percentage of time spent in the novel-texture arm was higher in the controls than in the IGF-IR ${ }^{-1-}$ mice ( $n=13$ animals; tamoxifen vs control, ${ }^{* *} p<0.01$, two-way ANOVA with post hoc Bonferroni multiple-comparisons test). $D$, Left, The control and the IGF-IR ${ }^{-1-}$ mice showed a similar performance in the gap-crossing test, indicating that there were no alterations in their sensory perception ( $n=5$; tamoxifen vs control, ns). Right, No differences were observed between the control and the IGF-IR ${ }^{-1-}$ mice in the Y-maze spontaneous alternation task, indicating a similar working memory ( $n=5$; tamoxifen vs control, ns; two-way ANOVA with post hoc Bonferroni multiple-comparisons test).

The only evidence suggesting this mode of action is seen in the hippocampus where IGF-I, possibly acting via GABAergic neurons, can induce the release of GABA to regulate endogenous ACh release (Seto et al., 2002). Nevertheless, our observations 
contribute to the notion that IGF-I can modulate both excitatory and inhibitory synaptic activity throughout the CNS.

Although there is evidence showing that insulin signaling in astrocytes mediates tyrosine phosphorylation of Munc18cand syntaxin-4-dependent ATP exocytosis, which in turn modulates presynaptic dopamine release (Cai et al., 2018), we have not found any previous evidence for any stimulatory action of IGF-I on ATP release by astrocytes. In this regard, it has been shown previously that metabotropic protease-activated receptor 1 (PAR-1) induces exocytosis of ATP from cortical astrocytes, which leads to a short-term downregulation of inhibitory synaptic currents in layer II/III pyramidal neurons (Lalo et al., 2014). In contrast with the presynaptic LTD described herein, this short-term modulation is mediated by a postsynaptic mechanism in which $\mathrm{Ca}^{2+}$ entry through the neuronal $\mathrm{P} 2 \mathrm{X}$ purine receptor leads to a phosphorylation-dependent downregulation of $\mathrm{GABA}_{\mathrm{A}}$ receptors. Therefore, astrocytes can downregulate or upregulate inhibitory synaptic transmission by a calcium-dependent release of ATP depending on whether IGF-IR or PAR-1 receptor, respectively, is activated.

Astrocytes have been shown to respond to both glutamate and GABA (Pasti et al., 1997; Kang et al., 1998; Guthrie et al., 1999; Navarrete and Araque, 2008, 2010), which allows them to sense the activity of excitatory and inhibitory neurons. In response to these neurotransmitters, they can release both glutamate and ATP/Ado (Min et al., 2012; Araque et al., 2014; De Pittà et al., 2016; Guerra-Gomes et al., 2018; Savtchouk and Volterra, 2018). In fact, hippocampal interneuron activity leads to $\mathrm{GABA}_{\mathrm{B}}$ receptor-mediated release of glutamate from astrocytes that potentiates both inhibitory (Kang et al., 1998) and excitatory (Perea et al., 2016) synaptic transmission. In addition to glutamate, hippocampal astrocytes may also release ATP, which is converted to adenosine that depresses (Pascual et al., 2005; Serrano et al., 2006; Andersson et al., 2007; Chen et al., 2013) or potentiates excitatory synaptic transmission (Panatier et al., 2011). Moreover, ATP released by astrocytes can depress excitatory synapses from basolateral amygdala and enhance inhibitory synapses from the lateral subdivision of the central amygdala via the activation of $\mathrm{A}_{1}$ and $\mathrm{A}_{2 \mathrm{~A}}$ adenosine receptors, respectively (Martin-Fernandez et al., 2017). Furthermore, cortical astrocytes have been shown to induce a short-term depression of inhibitory synaptic currents (Lalo et al., 2014). However, to our knowledge, our research is the first evidence that IGF-IR activation in astrocytes can induce a long-lasting depression of inhibitory cortical synaptic transmission through the release of ATP/Ado via a presynaptic mechanism. Therefore, we are presenting novel data showing that not only does the astrocytemediated $\mathrm{LTP}_{\mathrm{IGFI}}$ and its physiological consequence favor the associative synaptic plasticity described by Donald Hebbs, but also a novel mechanism in which IGF-I would induce cortical plasticity through the activation of adenosine receptors.

At the circuit level, interneurons control the flow of information and synchronization in the cerebral cortex. Synaptic inhibition is involved in the emergence of fast brain rhythms (Csicsvari et al., 2003) and in the induction of synaptic plasticity (Hensch, 2005), which jointly contribute to cognitive functions. Indeed, disruption of astrocytic vesicular release has been found to be crucial for gamma oscillatory hippocampal activity with a significant impact on recognition memory tasks (Lee et al., 2014). On the other hand, cortical astrocytes respond to sensory inputs and control sensory-evoked cortical neuronal network activity, indicating that astrocytes are actively involved in cortical sensory information processing (Lines et al., 2020). Our results demonstrate that the IGF-I receptor on astrocytes improves the performance of texture discrimination in mice, suggesting that the LTD $_{\text {IGFI }}$ is essential in this dependent task. The release of ATP/Ado from astrocytes and the LTD $_{\text {IGFI }}$ described here play a relevant role in this cognitive function by controlling brain rhythms and favoring the induction of Hebbian synaptic plasticity. Decreased synaptic inhibition would facilitate the backpropagation of action potentials into the dendrites and the induction of spike timing-dependent plasticity. Furthermore, by changing the ratio between synaptic excitation and inhibition, neuronal membranes can rapidly reach the threshold for action potential generation, and enhanced cortical activity is expected when cortical levels of IGF-I increase. Indeed, this increase in cortical activity would activate the neurotrophic coupling mechanism for the entrance of IGF-I from the plasma into the brain (Nishijima et al., 2010).

IGF-I is able to enhance glutamatergic synaptic transmission in the hippocampal slices of juvenile rats through a mechanism that involves AMPA, but not NMDA, postsynaptic receptors (Ramsey et al., 2005). However, IGF-I significantly increases both AMPA- and NMDA-mediated synaptic transmission by a postsynaptic mechanism in young adults and mature rats (Molina et al., 2012). Additionally, the increase in the expression levels of the NMDA receptor subunits $2 \mathrm{~A}$ and $2 \mathrm{~B}$ at the hippocampus by IGF-I in aged rats (Sonntag et al., 2000) may facilitate LTP induction. As in the hippocampus, we have shown that IGF-I increases the efficacy of excitatory synaptic transmission. The short-term potentiation of the EPSCs by IGF-I would establish a temporal window in which the threshold for inducing the Hebbian LTP would be the lowest because of the modulation of both excitation and inhibition by IGF-I. According to this scenario, another question arises as to how the IGF-IR activation on astrocytes is linked with the release of ATP. However, these questions should be the subject of analyses of further details in future articles.

In summary, our findings reveal novel mechanisms and functional consequences of IGF-I signaling in the cortex. It induces the long-lasting depression of inhibition and short enhancement of the excitation opening a temporal window to favor the generation of associative memories that impact on the behavioral performance of barrel cortex-related texture discrimination tasks, through the activation of cortical astrocytes.

\section{References}

Adamsky A, Kol A, Kreisel T, Doron A, Ozeri-Engelhard N, Melcer T, Refaeli R, Horn H, Regev L, Groysman M, London M, Goshen I (2018) Astrocytic activation generates de novo neuronal potentiation and memory enhancement. Cell 174:59-71.e14.

Aleman A, Torres-Alemán I (2009) Circulating insulin-like growth factor I and cognitive function: neuromodulation throughout the lifespan. Prog Neurobiol 89:256-265.

Andersson M, Blomstrand F, Hanse E (2007) Astrocytes play a critical role in transient heterosynaptic depression in the rat hippocampal CA1 region. J Physiol 585:843-852.

Andrade-Talavera Y, Duque-Feria P, Paulsen O, Rodríguez-Moreno A (2016) Presynaptic spike timing-dependent long-term depression in the mouse hippocampus. Cereb Cortex 26:3637-3654.

Araque A, Carmignoto G, Haydon PG (2001) Dynamic signaling between astrocytes and neurons. Annu Rev Physiol 63:795-813.

Araque A, Carmignoto G, Haydon PG, Oliet SHR, Robitaille R, Volterra A (2014) Gliotransmitters travel in time and space. Neuron 81:728-739.

Araujo DM, Lapchak PA Collier B, Chabot JG, Quirion R (1989) Insulin-like growth factor-1 (somatomedin-C) receptors in the rat brain: distribution and interaction with the hippocampal cholinergic system. Brain Res 484:130-138. 
Barnéoud P, Gyger M, Andrés F, van der Loos H (1991) Vibrissa-related behavior in mice: transient effect of ablation of the barrel cortex. Behav Brain Res 44:87-99.

Barros-Zulaica N, Castejon C, Nuñez A (2014) Frequency-specific response facilitation of supra and infragranular barrel cortical neurons depends on NMDA receptor activation in rats. Neuroscience 281:178-194.

Cai W, Xue C, Sakaguchi M, Konishi M, Shirazian A, Ferris HA, Li ME, Yu R, Kleinridders A, Pothos EN, Kahn CR (2018) Insulin regulates astrocyte gliotransmission and modulates behavior. J Clin Invest 128:2914-2926.

Carro E, Nuñez A, Busiguina S, Torres-Aleman I (2000) Circulating insulinlike growth factor I mediates effects of exercise on the brain. Trends Neurosci 29:474-480.

Carvell GE, Simons DJ (1990) Biometric analyses of vibrissal tactile discrimination in the rat. J Neurosci 10:2638-2648.

Castro-Alamancos MA, Torres-Aleman I (1993) Long-term depression of glutamate-induced gamma-aminobutyric acid release in cerebellum by insulin-like growth factor I. Proc Natl Acad Sci U S A 82:11-20.

Castro-Alamancos MA, Arevalo MA, Torres-Aleman I (1996) Involvement of protein kinase $\mathrm{C}$ and nitric oxide in the modulation by insulin-like growth factor-I of glutamate-induced GABA release in the cerebellum. Neuroscience 70:843-847.

Chen J, Tan Z, Zeng L, Zhang X, He Y, Gao W, Wu X, Li Y, Bu B, Wang W, Duan S (2013) Heterosynaptic long-term depression mediated by ATP released from astrocytes. Glia 61:178-191.

Chisholm NC, Sohrabji F (2016) Astrocytic response to cerebral ischemia is influenced by sex differences and impaired by aging. Neurobiol Dis 85:245-253.

Clark KA, Randall AD, Collingridge GL (1994) A comparison of paired-pulse facilitation of AMPA and NMDA receptor-mediated excitatory postsynaptic currents in the hippocampus. Exp Brain Res 101:272-278.

Creager R, Dunwiddie T, Lynch G (1980) Paired-pulse and frequency facilitation in the CA1 region of the in vitro rat hippocampus. J Physiol 299:409-424.

Csicsvari J, Jamieson B, Wise KD, Buzsáki G (2003) Mechanisms of gamma oscillations in the hippocampus of the behaving rat. Neuron 37:311-322.

De Pittà M, Brunel N, Volterra A (2016) Astrocytes: orchestrating synaptic plasticity? Neuroscience 323:43-61.

Deijen JB, De BH, Blok GJ, Van Der Veen EA (1996) Cognitive impairments and mood disturbances in growth hormone deficient men. Psychoneuroendocrinology 21:313-322.

Dellu F, Contarino A, Simon H, Koob GF, Gold LH (2000) Genetic differences in response to novelty and spatial memory using a two-trial recognition task in mice. Neurobiol Learn Mem 73:31-48.

Díez-García A (2017) Corrigendum: bidirectional Hebbian plasticity induced by low-frequency stimulation in basal dendrites of rat barrel cortex layer 5 pyramidal neurons. Front Cell Neurosci 11:112.

Fernandez AM, Fernandez S, Carrero P, Garcia-Garcia M, Torres-Aleman I (2007) Calcineurin in reactive astrocytes plays a key role in the interplay between proinflammatory and anti-inflammatory signals. J Neurosci 27:8745-8756

Fox K (1992) A critical period for experience-dependent synaptic plasticity in rat barrel cortex. J Neurosci 12:1826-1838.

Ganat YM, Silbereis J, Cave C, Ngu H, Anderson GM, Ohkubo Y, Ment LR, Vaccarino FM (2006) Early postnatal astroglial cells produce multilineage precursors and neural stem cells in vivo. J Neurosci 26:8609-8621.

García-Cáceres C, Quarta C, Varela L, Gao Y, Gruber T, Legutko B, Jastroch M, Johansson P, Ninkovic J, Yi C-X, Le Thuc O, Szigeti-Buck K, Cai W, Meyer CW, Pfluger PT, Fernandez AM, Luquet S, Woods SC, TorresAlemán I, Kahn CR, et al. (2016) Astrocytic insulin signaling couples brain glucose uptake with nutrient availability. Cell 166:867-880.

Garwood CJ, Ratcliffe LE, Morgan SV, Simpson JE, Owens H, VazquezVillaseñor I, Heath PR, Romero IA, Ince PG, Wharton SB (2015) Insulin and IGF1 signalling pathways in human astrocytes in vitro and in vivo; characterisation, subcellular localisation and modulation of the receptors. Mol Brain 8:51.

Gazit N, Vertkin I, Shapira I, Helm M, Slomowitz E, Sheiba M, Mor Y, Rizzoli S, Slutsky I (2016) IGF-1 receptor differentially regulates spontaneous and evoked transmission via mitochondria at hippocampal synapses. Neuron 89:583-597.

Guerra-Gomes S, Sousa N, Pinto L, Oliveira JF (2018) Functional roles of astrocyte calcium elevations: from synapses to behavior. Front Cell Neurosci 11:427.
Guthrie PB, Knappenberger J, Segal M, Bennett MVL, Charles AC, Kater SB (1999) ATP released from astrocytes mediates glial calcium waves. J Neurosci 19:520-528.

Hausrat TJ, Muhia M, Gerrow K, Thomas P, Hirdes W, Tsukita S, Heisler FF, Herich L, Dubroqua S, Breiden P, Feldon J, Schwarz JR, Yee BK, Smart TG, Triller A, Kneussel M (2015) Radixin regulates synaptic GABA A receptor density and is essential for reversal learning and shortterm memory. Nat Commun 6:6872.

Haydon PG, Carmignoto G (2006) Astrocyte control of synaptic transmission and neurovascular coupling. Physiol Rev 86:1009-1031.

Hensch TK (2005) Critical period plasticity in local cortical circuits. Nat Rev Neurosci 6:877-888.

Hernandez-Garzón E, Fernandez AM, Perez-Alvarez A, Genis L, Bascuñana P, Fernandez de la Rosa R, Delgado M, Angel Pozo M, Moreno E, McCormick PJ, Santi A, Trueba-Saiz A, Garcia-Caceres C, Tschöp MH, Araque A, Martin ED, Torres Aleman I (2016) The insulin-like growth factor I receptor regulates glucose transport by astrocytes. Glia 64:19621971.

Hirrlinger PG, Scheller A, Braun C, Hirrlinger J, Kirchhoff F (2006) Temporal control of gene recombination in astrocytes by transgenic expression of the tamoxifen-inducible DNA recombinase variant CreERT2. Glia 54:11-20.

Hutson KA, Masterton RB (1986) The sensory contribution of a single vibrissa's cortical barrel. J Neurophysiol 56:1196-1223.

Kang J, Jiang L, Goldman SA, Nedergaard M (1998) Astrocyte-mediated potentiation of inhibitory synaptic transmission. Nat Neurosci 1:683692.

Koltowska-Häggström M, Mattsson AF, Monson JP, Kind P, Badia X, Casanueva FF, Busschbach J, Koppeschaar HPF, Johannsson G (2006) Does long-term GH replacement therapy in hypopituitary adults with GH deficiency normalise quality of life? Eur J Endocrinol 155:109-119.

Kuhnt U, Voronin LL (1994) Interaction between paired-pulse facilitation and long-term potentiation in area cal of guinea-pig hippocampal slices: application of quantal analysis. Neuroscience 62:391-397.

Lalo U, Palygin O, Rasooli-Nejad S, Andrew J, Haydon PG, Pankratov Y (2014) Exocytosis of ATP from astrocytes modulates phasic and tonic inhibition in the neocortex. PLoS Biol 12:e1001747.

Lee HS, Ghetti A, Pinto-Duarte A, Wang X, Dziewczapolski G, Galimi F, Huitron-Resendiz S, Piña-Crespo JC, Roberts AJ, Verma IM, Sejnowski TJ, Heinemann SF (2014) Astrocytes contribute to gamma oscillations and recognition memory. Proc Natl Acad Sci U S A 111:E3343-E3352.

Lijffijt M, Van Dam PS, Kenemans JL, Koppeschaar HPF, de Vries WR, Drent ML, Wittenberg A, Kemner C (2003) Somatotropic-axis deficiency affects brain substrates of selective attention in childhood-onset growth hormone deficient patients. Neurosci Lett 353:123-126.

Lines J, Martin ED, Kofuji P, Aguilar J, Araque A (2020) Astrocytes modulate sensory-evoked neuronal network activity. Nat Commun 11:3689.

Liu Z, Chen Z, Shang C, Yan F, Shi Y, Zhang J, Qu B, Han H, Wang Y, Li D, Südhof TC, Cao P (2017) IGF1-dependent synaptic plasticity of mitral cells in olfactory memory during social learning. Neuron 95:106-122.e5.

Lübke J, Egger V, Sakmann B, Feldmeyer D (2000) Columnar organization of dendrites and axons of single and synaptically coupled excitatory spiny neurons in layer 4 of the rat barrel cortex. J Neurosci 20:5300-5311.

Maglio LE, Noriega-Prieto JA, Maraver MJ, Fernández de Sevilla D (2018) Endocannabinoid-dependent long-term potentiation of synaptic transmission at rat barrel cortex. Cereb Cortex 28:1568-1581.

Martin-Fernandez M, Jamison S, Robin LM, Zhao Z, Martin ED, Aguilar J, Benneyworth MA, Marsicano G, Araque A (2017) Synapse-specific astrocyte gating of amygdala-related behavior. Nat Neurosci 20:1540-1548.

Maya-Vetencourt JF, Baroncelli L, Viegi A, Tiraboschi E, Castren E, Cattaneo A, Maffei L (2012) IGF-1 restores visual cortex plasticity in adult life by reducing local GABA levels. Neural Plast 2012:250421.

Min R, Santello M, Nevian T (2012) The computational power of astrocyte mediated synaptic plasticity. Front Comput Neurosci 6:93.

Molina DP, Ariwodola OJ, Linville C, Sonntag WE, Weiner JL, BrunsoBechtold JK, Adams MM (2012) Growth hormone modulates hippocampal excitatory synaptic transmission and plasticity in old rats. Neurobiol Aging 33:1938-1949.

Mysoet J, Dupont E, Bastide B, Canu MH (2015) Role of IGF-1 in cortical plasticity and functional deficit induced by sensorimotor restriction. Behav Brain Res 290:117-123. 
Navarrete M, Araque A (2008) Endocannabinoids mediate neuron-astrocyte communication. Neuron 57:883-893.

Navarrete M, Araque A (2010) Endocannabinoids potentiate synaptic transmission through stimulation of astrocytes. Neuron 68:113-126.

Nedergaard M, Ransom B, Goldman SA (2003) New roles for astrocytes: redefining the functional architecture of the brain. Trends Neurosci 26:523-530.

Nilsson L, Sara VR, Nordberg A (1988) Insulin-like growth factor 1 stimulates the release of acetylcholine from rat cortical slices. Neurosci Lett $88: 221-226$

Nishijima T, Piriz J, Duflot S, Fernandez AM, Gaitan G, Gomez-Pinedo U, Verdugo JMG, Leroy F, Soya H, Nuñez A, Torres-Aleman I (2010) Neuronal activity drives localized blood-brain-barrier transport of serum insulin-like growth factor-I into the CNS. Neuron 67:834-846.

Nuñez A, Carro E, Torres-Aleman I (2003) Insulin-like growth factor I modifies electrophysiological properties of rat brain stem neurons. J Neurophysiol 89:3008-3017.

Ocrant I, Valentino KL, Eng LF, Hintz RL, Wilson DM, Rosenfeld RG (1988) Structural and immunohistochemical characterization of insulin-like growth factor I and II receptors in the murine central nervous system. Endocrinology 123:1023-1034.

Panatier A, Vallée J, Haber M, Murai KK, Lacaille JC, Robitaille R (2011) Astrocytes are endogenous regulators of basal transmission at central synapses. Cell 146:785-798.

Parpura V, Zorec R (2010) Gliotransmission: exocytotic release from astrocytes. Brain Res Rev 63:83-92.

Pascual O, Casper KB, Kubera C, Zhang J, Revilla-Sanchez R, Sul JY, Takano H, Moss SJ, McCarthy K, Haydon PG (2005) Astrocytic purinergic signaling coordinates synaptic networks. Science 310:113-116.

Pasti L, Volterra A, Pozzan T, Carmignoto G (1997) Intracellular calcium oscillations in astrocytes: a highly plastic, bidirectional form of communication between neurons and astrocytes in situ. J Neurosci 17:7817-7830.

Perea G, Araque A (2007) Astrocytes potentiate transmitter release at single hippocampal synapses. Science 317:1083-1086.

Perea G, Navarrete M, Araque A (2009) Tripartite synapses: astrocytes process and control synaptic information. Trends Neurosci 32:421-431.

Perea G, Gómez R, Mederos S, Covelo A, Ballesteros JJ, Schlosser L, Hernández-Vivanco A, Martín-Fernández M, Quintana R, Rayan A, Díez A, Fuenzalida M, Agarwal A, Bergles DE Bettler B, Manahan-Vaughan D, Martín ED, Kirchhoff F, Araque A (2016) Activity-dependent switch of gabaergic inhibition into glutamatergic excitation in astrocyte-neuron networks. Elife 5:e20362.

Pfaffl MW (2001) A new mathematical model for relative quantification in real-time RT-PCR. Nucleic Acids Res 29:e45.
Ramsey MM, Adams MM, Ariwodola OJ, Sonntag WE, Weiner JL (2005) Functional characterization of Des-IGF-1 action at excitatory synapses in the CA1 region of rat hippocampus. J Neurophysiol 94:247-254.

Rodriguez-Perez AI, Borrajo A, Diaz-Ruiz C, Garrido-Gil P, LabandeiraGarcia JL (2016) Crosstalk between insulin-like growth factor-1 and angiotensin-II in dopaminergic neurons and glial cells: role in neuroinflammation and aging. Oncotarget 7:30049-30067.

Ross JL (2005) Effects of growth hormone on cognitive function. Horm Res 64:89-94.

Sarter M, Bodewitz G, Stephens DN (1988) Attenuation of scopolamineinduced impairment of spontaneous alternation behaviour by antagonist but not inverse agonist and agonist beta-carbolines. Psychopharmacology (Berl) 94:491-495.

Savtchouk I, Volterra A (2018) Gliotransmission: beyond black-and-white. J Neurosci 38:14-25.

Serrano A, Haddjeri N, Lacaille J-C, Robitaille R (2006) GABAergic network activation of glial cells underlies hippocampal heterosynaptic depression. J Neurosci 26:5370-5382.

Seto D, Zheng WH, McNicoll A, Collier B, Quirion R, Kar S (2002) Insulinlike growth factor-I inhibits endogenous acetylcholine release from the rat hippocampal formation: possible involvement of GABA in mediating the effects. Neuroscience 115:603-612.

Singh P, Jorgačevski J, Kreft M, Grubišić V, Stout RF, Potokar M, Parpura V, Zorec R (2014) Single-vesicle architecture of synaptobrevin2 in astrocytes. Nat Commun 5:3780.

Sonntag WE, Bennett SA, Khan AS, Thornton PL, Xu X, Ingram RL, BrunsoBechtold JK (2000) Age and insulin-like growth factor-1 modulate Nmethyl-D-aspartate receptor subtype expression in rats. Brain Res Bull 51:331-338

Sytze van Dam P (2005) Neurocognitive function in adults with growth hormone deficiency. Horm Res 64:109-114.

Trejo JI, Piriz J, Llorens-Martin MV, Fernandez AM, Bolós M, LeRoith D, Nuñez A, Torres-Aleman I (2007) Central actions of liver-derived insulin-like growth factor I underlying its pro-cognitive effects. Mol Psychiatry 12:1118-1128.

Tsai CL, Wang CH, Pan CY, Chen FC (2015) The effects of long-term resistance exercise on the relationship between neurocognitive performance and GH, IGF-1, and homocysteine levels in the elderly. Front Behav Neurosci 9:23.

Volterra A, Meldolesi J (2005) Astrocytes, from brain glue to communication elements: the revolution continues. Nat Rev Neurosci 6:626-640.

Zhou X, Herman JP, Paden CM (1999) Evidence that IGF-I acts as an autocrine/paracrine growth factor in the magnocellular neurosecretory system: neuronal synthesis and induction of axonal sprouting. Exp Neurol 159:419-432.

Zucker RS (1999) Calcium- and activity-dependent synaptic plasticity. Curr Opin Neurobiol 9:305-313. 